\title{
The impact of ICT diffusion on sovereign cost of debt
}

\author{
Apostolos Kotzinos ${ }^{\mathrm{a}}$, Dimitris Psychoyios ${ }^{\mathrm{a}}{ }^{1}$, Nikolaos Vlastakis ${ }^{\mathrm{b}}$, \\ ${ }^{a}$ Department of Industrial Management \& Technology, University of Piraeus, Greece \\ ${ }^{b}$ Essex Business School, University of Essex, UK
}

\begin{abstract}
We examine the effect of a country's level of information and communication technologies (ICT) diffusion on its credit rating and cost of debt. ICT diffusion is approximated using the Networked Readiness Index, which is designed to capture a country's capacity and preparedness to participate in the digital economy. We adopt a modified random effects approach which allows us to distinguish between short and long run effects on a dataset of 65 countries for a time span of ten years. We show that ICT have a significant impact on a country's credit rating and cost of debt which is robust to the presence of other variables proposed in the literature. The effect is stronger for nonOECD countries, indicating a pathway for developing countries to improve their access to debt markets. Our conclusions are robust to the advent of the recent financial crisis.
\end{abstract}

Keywords: Credit ratings; Sovereign debt; Information and Communication Technologies; Ereadiness; Developing countries

JEL Codes: C23, E43, E44, F34, G24, H63, O33

\section{Acknowledgements}

This research has been partly supported by the University of Piraeus Research Center.

\footnotetext{
${ }^{1}$ Corresponding author: University of Piraeus, Department of Industrial Management, 107 Deligiorgi Str., Piraeus, GR 185 34, Greece. Tel.: (+30) 2104142399

E-mail addresses: tolisk@unipi.gr (A. Kotzinos), dpsycho@unipi.gr (D. Psychoyios), nvlast@essex.ac.uk (N. Vlastakis),
} 


\section{Introduction}

Investment in Information and Communication Technologies (ICT henceforth) is considered a pathway to economic development by both academics (see, for example Indjikian and Siegel, 2005) and policy makers (e.g. UN, 2005). ICT is viewed as a General Purpose Technology (GPT) that spreads throughout the economy and significantly influences a variety of sectors enabling the creative use of labour and the restructuring of organizational assets, thus improving products and processes (Holt and Jamison, 2009). The presence of network externalities, production spillovers and lower information costs forces businesses to change the way they operate in order to fully realize the benefits of ICT (Stiroh, 2003).

Beginning in the mid-1990s the US economy experienced a major surge in labour productivity and grew in a surprisingly fast pace achieving at the same time low unemployment and inflation rates. This period coincided with significant investment in, and the diffusion of, ICT; US firms pumped more than $\$ 3$ trillion during the1980s and 1990s into ICT investment, defined to include computer hardware, computer software and telecommunication equipment (Stiroh, 2003). The popular view is that ICT have been the major driver and played a substantial role in explaining the sustained growth rates. The term "new or digital economy", was coined by business press to depict a superior economic structure that arises as the joined outcome of globalization and ICT boost; signaling that the workings of the economy may have significantly changed with rules, principles, institutions that go well beyond those of traditional economy (Schreyer, 2000).

Notwithstanding, the impact of ICT is indirect and is mainly felt through the way it is used to transform the economy and enable factors that foster productivity and GDP growth (similarly to electricity). As a result, the precise measurement of the effects of ICT to the economy is a challenging task (Jalava and Pohjola, 2002), a fact that explains the somewhat conflicting results presented in the extant literature. Typically, early studies, examining periods before the beginning of the 1990s report negative results while later studies tend to uncover a more positive and rather stable impact of ICT to growth (Papaioannou and Dimelis, 2007). Typical examples of the latter include Oliner and Sichel (2000) and Jorgenson and Stiroh (2000) who concentrate on the US and suggest that ICT has been 
the underlying factor of the US economy resurgence in the 1990s. Similarly, positive results have been reported in an international setting by studies that include either developed countries (e.g. Morsink and Haacker, 2002) or both developed and developing countries (e.g. Vu, 2011; Papaioannou and Dimelis, 2007). Conversely, other researchers report the opposite findings both in the US (Gordon, 2000) and the international (Schreyer, 2000) context.

In this paper we extend the literature by considering the effects of ICT on sovereign credit ratings and cost of debt. Most of the academic research focuses on the effects of ICT to growth (usually GDP). A relatively smaller number of studies attempt to provide better insights on how this relationship works by examining the effect of ICT on other macroeconomic fundamentals like inflation (Yi and Choi, 2005), employment (Crandall et al., 2007; Ugur and Mitra, 2017) and foreign direct investment (FDI) (Choi, 2003). The creditworthiness and cost of debt have received very limited attention in the literature. Nevertheless, the advent of the financial crisis of 2007-2008 and the subsequent sovereign debt crisis, which resulted to several sovereigns being excluded from debt markets, underlines the importance of examining the effect that ICT has at a country level on the costs and risks of borrowing.

The study that is closest to ours is Bissoondoyal-Bheenick et.al. (2006) who use an ordered response model to examine the determinants of sovereign credit ratings. They find that alongside with purely economic variables like inflation, GNP per capita, current account balance and level of foreign reserves, the diffusion of technology, proxied by the usage of mobile phones is the most significant determinant of sovereign credit ratings. Our study is different to theirs in several ways. Firstly, instead of a somewhat narrowly-specified measure of technology diffusion like the use of mobile phones, we focus on the comprehensive concept of a country's e-readiness, as proxied by the Networked Readiness Index (NRI). E-readiness is a relatively new concept that evolved while striving to provide a unified framework of evaluation of the rapid rate of internet penetration throughout the world, the dramatic advance in the use of ICT in business and industry as well as the depth of the digital divide between more and less developed countries (Grigorovici et.al., 2004, Hanafizadeh et.al., 2009). 
Geiger and Mia (2009) discuss the advantages of e-readiness over mobile telephony diffusion as a measure of ICT penetration. Moreover, we model the impact of ICT diffusion not only on credit ratings, but also on the cost of debt. This allows for a more robust analysis since one can generally expect a higher level of within country-year variation in the cost of debt than in credit ratings, which lends more power to our results. Finally, we follow a panel regression approach, as opposed to a cross-sectional one, with obvious advantages due to the availability of the time dimension.

We employ a dataset comprising 65 countries between the years 2001-2010. Our main hypothesis is that e-readiness will have a significant effect on credit ratings and cost of debt due to the way ICT re-shape the economy and impact growth, directly and through spillovers, as has been suggested by Jorgenson and Stiroh (2000), and Oliner and Sichel (2000). Our sample contains both OECD and non-OECD countries, thus we are able to test whether the impact of e-readiness on ratings and cost of debt is different between developed and developing countries, an issue that has been debated extensively in the literature. Several studies suggest that ICT impact is stronger for developed countries since they enjoy a better telecommunication infrastructure that allow them to fully realize the benefits from ICT (see, among others, Papaioannou and Dimelis, 2007). Such concerns are strengthened by the possible presence of network effects in the application of ICT (Quianget.al., 2004, Lucas and Sylla, 2003); massive gains from ICT can be enjoyed after a critical mass of ICT investment and usage is reached. However, other researchers (e.g. Luo and Bu, 2016; Seoet.al., 2009; $\mathrm{Vu}, 2011$; Waverman et.al., 2005; Jorgenson and $\mathrm{Vu}, 2010$ ) argue that ICT comprise a unique opportunity for developing countries to leapfrog to a higher level of development and experience the potential advantages of being a late-comer.

The most important contributions of our paper can be summarized as follows: Firstly, we are the first to study the impact of e-readiness on sovereign credit ratings and cost of debt. Moreover, our dataset allows us to test the hypothesis that the effects of e-readiness on credit ratings and cost of debt are different between developed and developing countries. Finally, we examine whether this relationship has remained unchanged in the time before and after the recent financial crisis. Overall, 
our results confirm that e-readiness is a significant determinant of credit ratings and cost of debt, with higher e-readiness levels associated with improved credit ratings and lower cost of debt. The results also confirm that this relationship is stronger for developing countries, a fact that indicates a path for developing countries to improve their credit profile. Our results are robust to the advent of the financial crisis.

The rest of the paper is structured as follows. The next section discusses our research hypotheses and methodology. Section 3 presents our data and empirical analysis and discusses the results. The final section concludes the paper.

\section{Research questions and methodology}

\subsection{Hypotheses formulation}

Motivated by the positive economic effects of a country's high level of ICT diffusion that have been discussed in the literature, our first hypothesis is:

H1 $1_{0}$ A country's credit rating and sovereign debt interest rates are related to its e-readiness, with higher e-readiness levels associated with improved credit ratings and lower cost of debt.

As we elaborated in section 1, the diffusion of ICT increases efficiency and productivity and may lead to enhanced quality and a diminished cost of a more transparent governance. More strictly, the output of a national economy is related to various production inputs such as labour, physical capital and purchased material, as well as to the level of technology (Solow, 1957). ICT is a core dimension of the current technological progress. ICT impacts the growth of productivity in three main stages. First, ICT facilitates innovation in various producing sectors of the economy. Second, the innovative outputs (products) of these sectors rapidly dominate the market resulting to a fall of their prices which permits an accumulation of them as capital in other sectors of the economy. Third, the need of the firms to incorporate in their production processes the newly accumulated capital triggers a restructuring of organizational assets that responds to these technological changes and maximizes their effectiveness (Morsink and Haacker, 2002). 
Governments as well may benefit from ICT in order to minister to the needs of their citizens. Improved processes and digital connections within and between state, businesses and public (Heeks, 2001) are the two main contribution of ICT to government functions. The digital transformation of these functions can also become a leading tool against corruption by limiting human interference and paperwork and enhancing accountability and transparency.

Moreover, in developing countries ICT constitute the only available way for providing basic services, especially in rural areas, like education, healthcare and banking transactions; the absence of which hinders any development opportunity. As Vu (2011), Jorgenson and Vu (2010) and Wavermanet.al., (2005), suggest, contradicting the findings of other researchers like (Papaioannou and Dimelis, 2007; Lucas and Sylla, 2003; Quianget.al., 2004), ICT comprise a more important determinant of growth opportunities for developing countries. Motivated by their work we formulate our second hypothesis:

H20: The relevance of a country's e-readiness to its credit rating and sovereign debt interest rates is not the same across different stages of economic development. E-readiness has a larger impact on credit ratings and cost of debt for developing and emerging economies as compared to developed economies.

This hypothesis stems also from the fact that in the next decade ICT will face a tremendous shift of domination towards the emerging economies. Developing countries at the moment drive over 80 percent of all new mobile subscriptions worldwide and as more citizens of those countries go online, gain access to mobile telephony and connectivity levels reach those of the developed countries, the former countries' global share of digital transactions will inevitably become predominant. China and India have already become key players in the world digital economy and are expected to play a major role in the future. Emerging economies face a unique opportunity and challenge, after years of underdevelopment and poverty for millions of their citizens, to enable access to primary services, fundamentally money and banking services to the, so far, unbankable and to leapfrog to higher stages of development by following their own, accustomed to their needs and 
necessities, technological pattern of best practices. Taking into account the vast technological opportunities that arise in the emerging economies, a higher level of e-readiness is expected to have a more significant impact on their economic growth than on developed ones and be appraised more positively by investors, lenders and agencies who mainly seek for profitable investment opportunities throughout the world, opportunities that could be given by those economies who enter the digital era with firm footstep.

\subsection{Methodological framework}

We employ a balanced panel data set that consists of sixty-five countries for a total of ten years. Let $Y_{i t}$ be the response variable, $X_{i t}$ be a vector of time-varying regressors and $Z_{i}$ be a vector of another set of time-invariant regressors. Let $\alpha_{i}$ be the unknown intercept for each country that does not vary over time, representing the combined effect on $Y_{i t}$ of all unobserved variables that are constant over time and $\epsilon_{i t}$ be the error term, representing the purely random variation at each point of time.

Our basic model will then be:

$$
Y_{i t}=\beta X_{i t}+\gamma Z_{i}+\alpha_{i}+\epsilon_{i t}
$$

These models can be tackled using pooled OLS, fixed effects or random effects. Although we assume statistical independence between $\alpha_{i}$ and $\epsilon_{i t}$, the allowance of any kind of correlation between $\alpha_{i}$, $X_{i t}$ and $Z_{i}$ will determine if we are going to use a fixed effects or a random effects approach. Following fixed effects means that we are going to allow for such correlation while random effects assumes that $\alpha_{i}$ is not correlated with regressors. It would be reasonable to suggest that the unobserved time-invariant variables that have an impact on $Y_{i t}$, given the number and the extended set of the included variables in the regression, are correlated with the vector $X_{i t}$ of time-varying regressors and therefore the use of fixed effects is appropriate and statistically sound. We also confirm this by running the fixed and random effects regressions and conducting a Hausman test which suggests that a random effects estimator would be inconsistent ${ }^{2}$.

\footnotetext{
${ }^{2}$ Results are available upon request from the authors.
} 
Despite the fluctuations that the economic crisis caused to credit risk ratings, agencies do not tend to change their ratings so often and so dramatically. Although consistent, fixed effects do not allow an estimation of coefficients for time-invariant variables (albeit we are still controlling them) and therefore, as Afonso et al., (2011) suggest, using fixed effects would only allow us to capture credit ratings' movements across time since the average rating would be captured by the countryspecific intercept $\alpha_{i}$. Furthermore, the literature review that follows in section 3.2 suggests that coefficients of time - invariant variables might be of interest. Given the limited within-country variation of credit ratings and other predictors across time, a fixed effects model could yield less efficient estimates.

As such, following Afonso et. al., (2011) and Allison (2009), we opt for a hybrid random effects model that, first, allows us to estimate coefficients for both time-variant and invariant regressors and, second, eliminates the correlation between the country specific error and the time variant regressors. We assume that the country specific intercept $\alpha_{i}$ is a linear combination of time-averages of the vector $X_{i t}$ of time-varying regressors. Therefore, we formally write:

$$
\alpha_{i}=\eta \bar{X}_{i}+e_{i}
$$

where $e_{i}$ is the random error term. Substituting equation (2) in equation (1) we obtain:

$$
Y_{i t}=\beta X_{i t}+\gamma Z_{i}+\eta \bar{X}_{i}+e_{i}+\varepsilon_{i t}
$$

Adding in both sides of equation 3 the $\beta \bar{X}_{i}$ term, it can be written as:

$$
Y_{i t}=\beta\left(X_{i t}-\bar{X}_{i}\right)+(\beta+\eta) \bar{X}_{i}+\gamma Z_{i}+e_{i}+\varepsilon_{i t}
$$

The within $\left(X_{i t}-\bar{X}_{i}\right)$ and the between $\left(\bar{X}_{i}\right)$ panel variation are now completely separated. The $\beta$ coefficient can be interpreted as the short-run effect and $(\beta+\eta)$ as the long-run effect of the regressors that accounts for panel heterogeneity (Bartels, 2009). The model is estimated using random effects, which will allow us to estimate $(\beta+\eta)$ coefficients. Then, in order to check the validity of the results, we re-estimate the model using fixed effects, which is always consistent (although less efficient). If the coefficient estimates and their corresponding standard errors of the two models (fixed 
effects model and hybrid random effects model described in equation 4) are identical, both models perform equally well ${ }^{3}$. That is, the hybrid random effects model escapes the correlation problem we discussed earlier ${ }^{4}$.

Both $e_{i}$ and $\varepsilon_{i t}$ are assumed to be normally distributed around zero with variance $\sigma_{e}^{2}$ and $\sigma_{\varepsilon}^{2}$, respectively. The between-country error term is uncorrelated with the country mean centered covariates, since each such covariate has a mean of zero for each country (Bell and Jones 2015, Bartels 2009). In addition, between-country error term $\left(e_{i}\right)$ is assumed to be uncorrelated with the time invariant variables, i.e.:

$$
\begin{gathered}
\operatorname{Cov}\left(X_{i t}-\bar{X}_{\mathrm{i}}, e_{i}\right)=0 \\
\operatorname{Cov}\left(\bar{X}_{\mathrm{i}}, e_{i}\right)=0 \\
\operatorname{Cov}\left(Z_{i}, e_{i}\right)=0
\end{gathered}
$$

The above model can be generalized to an ordered response model, which has been suggested in the literature as more appropriate to the nature of credit ratings. In order to motivate our response model and following Bissoondoyal-Bheenick (2005), we consider a latent continuous variable which is dependent upon the same variables of equation (4). Therefore, we write:

$$
Y_{i t}^{*}=\beta\left(X_{i t}-\bar{X}_{i}\right)+(\beta+\eta) \bar{X}_{i}+\gamma Z_{i}+e_{i}+\varepsilon_{i t}
$$

Since the latent variable is unobservable and continuous, several cut off points are assumed to be employed by the agencies in order to assign the final rating in the following way:

$$
Y_{i t}=\left\{\begin{array}{l}
1 \text { if } y_{i t}^{*}<c_{1} \\
2 \text { if } C_{1}<y_{i t}^{*}<C_{2} \\
20 \text { if } c_{19}<y_{i t}^{*}<c_{20} \\
21 \text { if } y_{i t}^{*}>c_{20}
\end{array}\right.
$$

\footnotetext{
${ }^{3}$ Which is expected to a certain extent. According to Bell and Jones, (2015), since the mean term $\bar{X}_{i}$ of each time varying variable is only associated with the across countries variance, the estimates (and standard errors) of the time-variant coefficients will be identical to those of the fixed effects estimation (Mundlak, 1978).

${ }^{4}$ As such, there is no need to resort to alternative methods, such as the Hausman test, to differentiate between the fixed and random effects models, since the test also takes the form of comparing the vector of coefficient estimates of the models (Greene, 2012; Wooldridge, 2002).
} 
where the $c_{1}-c_{20}$ are the estimated threshold parameters ${ }^{5}$.

\section{Empirical application}

\subsection{A proxy for e-readiness}

Even though the various e-readiness measures strive to approximate the same characteristic, they share limited commonality in definitions, terms and methods they use. Most of the measures have largely adopted quantitative approaches that assign numerical scores on specific components of ereadiness tools to countries and use a compound index as weighted average that aggregates the scores into a single overall value that determines the level of e-readiness of the country. Usually these results are published annually or on regular intervals allowing a country to compare itself with other countries, as well as to compare its current position with that in the past. For the purpose of our empirical analysis, we have chosen the Networked Readiness Index (NRI) as the most suitable proxy for e-readiness (see, among others, Wu, et al., 2012; Keef, et. al, 2009). The NRI (first published in 2001, annually since then) is prepared by the World Economic Forum and INSEAD and it comprises of three components: the environment for IT; the readiness of the country's key stakeholders (individuals, businesses and governments) to use IT and the actual use of IT amongst these stakeholders. The final NRI score is a simple average of the three component scores.

Apart from the NRI, there are two more proxies, also popular amongst academics and practitioners, for the estimation of e-readiness (see Hanafizadeh, et al., 2009 for a literature review on e-readiness assessment measures). First, the EIU E-Readiness Index (published annually since 2000), which is published and prepared from the Economist Intelligence Unit (EIU) in cooperation with the IBM Institute for Business Value. The model consists of over 100 separate quantitative and qualitative criteria. The criteria are scored by the EIU's regional analysts and editors and are organized into six primary categories with a different impact in overall score. However, the NRI is

\footnotetext{
${ }^{5}$ Following Afonso et. al., (2011) we estimate the coefficients and cut-off points using maximum likelihood utilizing the procedure by Frechette (2001) in Stata. The aforementioned random effects ordered probit estimation regards both error terms to be normally distributed.
} 
available for a broader range of countries than EIU Index, thus facilitating the compilation of a richer data set $^{6}$. Second, the E-Government Readiness Index (published annually since 2003), which is prepared from the United Nations Division for Public Economics and Public Administration together with the American Society for Public Administration. The E-Government Readiness Index shows the level governments are aware and benefiting from ICT. As such, the E-Government Readiness Index is a "government" specific oriented index that does not reflect the concept of e-readiness to its entirety.

\subsection{Data and sources}

Rating agencies provide scarce evidence of the actual importance they allocate (Cantor and Packer, 1996; Reusens and Croux, 2017) to each of the numerous economic, social and political factors they suggest as determinants of a country's evaluation. Their methodology is a blend of quantitative analysis and subjective judgments (Bhatia, 2002) but the ultimate decision for each country is always taken by the ratings committee, a small group of senior analysts and experts and remains a black box. Therefore, a large body of empirical literature focuses on successfully modeling sovereign ratings.

Macroeconomic fundamentals associated with solvency, liquidity and economic or political stability have been widely proposed and acknowledged in literature as the driving factors behind sovereign ratings and cost of debt (Baek, 2005). Variables like growth of GDP (Maltritz, 2011), per capita income (Mellios, C., Paget-Blanc, E., 2006), external debt to GDP ratio (Cantor and Packer, 2006; Remolonaet.al., 2007), government budget surplus or deficit to GDP ratio (Bennell, 2006) can be grouped as solvency variables, since they show the government's ability to meet its debt service requirements. Liquidity variables illustrate the ability of a government to deal with fluctuations to foreign exchange receipts without delaying or rescheduling accrued debt payments in foreign currency (Feder and Uy, 1985). Usually, they are represented in literature by the current account balance (Baek, 2005) and the ratio of reserves to imports (Cruces and Trebesch, 2013). Economic and political stability are proxied by indices that measure the corruption, the human development and

\footnotetext{
${ }^{6} \mathrm{~A}$ correlation analysis shows a strong correlation between the two indices at the aggregate level.
} 
the protection of property rights (Mellios and Paget-Blanc, 2006; Bhatta et.al, 2018). They reflect the quality of the government and the risk of expropriation (Cruces and Trebesch, 2013). Moreover, annual rate of inflation is employed as a sign of prudent economic management (Haque et.al, 1996; Bissoondoyal-Bheenicket.al., 2006). Other factors that empirical literature has revealed as important factors behind credit ratings include, but not limit to, unemployment rates (BissoondoyalBheenicket.al., 2006), exchange rates volatility (Mellios and Paget-Blanc, 2006; Bhatta et.al, 2018), public debt (Reusens and Croux, 2017) and capacity to acquire taxes (Lemmen and Goodhart,1999).

Following the literature presented above, we employ a wide collection of time variant and invariant economic, financial and other variables for 65 countries, sampled in an annual frequency between 2001 and 2010. Table 1 shows the variables used throughout the paper, together with a brief description of them, the sources we used to collect them, and a sign of the presumed effect each variable is likely to have on credit rating risk and cost of debt on the basis of previous findings. In addition, we use a set of dummy time - invariant variables to indicate: First, the Eurozone membership, which in most of the years under scrutiny should be considered as providing profound economic advantages to member states but in late years (2009 -2010) could have a more ambiguous role since weakest members proved vulnerable to liquidity crises (Reusens and Croux, 2017) ${ }^{7}$. Second, the membership of OECD as a measure of development adopted by Ferriet.al. (1999). Third, the history of defaults whether, the more (1975-2010) or the less (1995-2010) distant in time, acts as a measure of country's willingness to repay its debt (Reusens and Croux, 2017; Cruces and Trebesch, 2013). Finally, the origin of a sovereign's legal system as a measure of the available legal remedies against sovereign debtors in default.

\section{[Insert Table 1 about here]}

Our sample of countries is grouped in two major clusters: The OECD group consists of 28 countries, namely Australia, Austria, Belgium, Canada, Czech Republic, Denmark, Finland, France, Germany, Greece, Hungary, Iceland, Ireland, Italy, Japan, Luxembourg, Netherlands, New Zealand,

\footnotetext{
${ }^{7}$ Since European debt crisis had not yet taken place or would be still in its infancy.
} 
Norway, Poland, Portugal, South Korea, Spain, Sweden, Switzerland, Turkey, United Kingdom and United States. The non-OECD group consists of 37 countries, namely Azerbaijan, Brazil, Bulgaria, Colombia, Costa Rica, Croatia, Dominican Republic, Egypt, El Salvador, Estonia, Ghana, Hong Kong, India, Indonesia, Israel, Jamaica, Jordan, Kazakhstan, Latvia, Lithuania, Malaysia, Moldova, Morocco, Nicaragua, Pakistan, Peru, Philippines, Qatar, Romania, Russia, Singapore, Slovenia, South Africa, Sri Lanka, Thailand, Trinidad and Tobago and Tunisia ${ }^{8}$.

The dependent variables aim to capture sovereign credit risk and cost of debt. Three different proxies of sovereign credit risk are employed, namely the credit ratings reported by the three major American agencies, Standard and Poor's (S\&P), Moody's and Fitch. Following standard practice in the literature (e.g. Afonso et.al., 2007; Bissoondoyal-Bheenick, 2005; Cantor and Packer, 1996) the qualitative letter ratings are linearly transformed to numerical equivalents with number 1 representing the highest score (AAA for S\&P and Fitch, Aaa for Moody's) and number 21 the lowest (D for S\&P and Fitch, C for Moody's). The transformation is straightforward and is presented in Table 2. Nevertheless, unlike other empirical studies that employ the attributed sovereign rating on the $31^{\text {st }}$ December of each year, we construct a weighted average rating, which assumes a fiscal year of 360 days, multiplies every assigned rating during the specific year by the days that this rating did not change, sums the products and then divides the sum by $360^{9}$. Finally, the result is rounded to the closest integer. The idea behind the constructed rating is that a single rating at just one point in time cannot comprise a satisfactory proxy of sovereign credit risk, since it disregards any upgrades or downgrades that took place during each year.

The sovereign cost of debt is proxied by the yield to maturity (YTM) of the 10-year zero coupon sovereign benchmark bond. If none available, then the closest maturity is selected. We were able to

\footnotetext{
${ }^{8}$ During 2010, Estonia, Israel and Slovenia signed the Convention on the Organization for Economic Co-operation and Development and became full members.

${ }^{9}$ Calculations are available upon request from the authors.
} 
obtain comparable bonds only for 36 out of the 65 countries of our sample, so our empirical analysis for YTMs will be confined to them ${ }^{10}$.

In order to obtain an "expanded" proxy of the sovereign cost of debt for more countries (expanded cost of debt - exCoD), we also use the JP Morgan Emerging Markets Bond Global Indices' stripped yield (EMBI), in the cases where no data for YTMs of sovereign benchmark bonds are available. The index tracks the total returns of external debt instruments, and it has been proposed in the literature as an alternative measure of cost of debt (Bhatta et. al., 2018). As such, data for fifteen additional countries has been added to the existing dataset of YTMs of the 36 countries. ${ }^{11}$

[Insert Table 2 about here]

\subsection{Descriptive statistics}

Summary statistics of the main variables for each country under study are depicted in Table 3 . The credit ratings and the yield to maturity exhibit a wide variability. In particular, yields to maturity range from 1.382 (Japan) to 11.318 (Colombia).

[Insert Table 3 about here]

Concerning the Networked Readiness Index, United States seize the first place with a mean of 5.595, followed by Singapore, with an average of 5.567 while the third place is occupied by Sweden with an average of 5.556. The index presents very similar variability for both OECD and non-OECD members (sd: 0.592 and 0.615 respectively). However, OECD members score about a unit higher with an average of 4.8576 , compared to an average of 3.8032 for non-OECD countries.

Table 4 presents all averages per variable and year for both OECD and non-OECD countries and the aggregate average for all years under study. The last two columns of Table 4 depict the percentage change between average values for 2001 and 2010 per variable and group of countries and the p-values of the Satterthwaite-Welch t-test between averages of variables across all years for

\footnotetext{
${ }^{10}$ The 36 countries under considerations are: Australia, Austria, Belgium, Bulgaria, Canada, Colombia, Czech Republic, Denmark, Finland, France, Germany, Greece, Hong Kong, Hungary, India, Ireland, Israel, Italy, Japan, Lithuania, Malaysia, Netherlands, New Zealand, Norway, Philippines, Poland, Portugal, Russia, Singapore, South Korea, Spain, Sweden, Switzerland, Thailand, United Kingdom and United States.

${ }^{11}$ The additional countries are: Brazil, Costa Rica, Croatia, Dominican Republic, Egypt, El Salvador, Kazakhstan, Morocco, Pakistan, Peru, Romania, South Africa, Trinidad and Tobago, Tunisia, and Turkey
} 
OECD and non-OECD countries. Table 4 shows that credit risk ratings have deteriorated for OECD countries between 2001 and 2010 as far as S\&P (-14.4 percent) and Fitch (-4.74 percent) is concerned, while Moody’s remained more optimistic (+2.81 percent). All agencies upgraded, on average, nonOECD countries, with Moody's improving its assigned credit ratings to non-OECD countries by 10.12 percent. The actual cost of debt has fallen sharply by 23.08 percent for OECD countries and 37.69 percent for non-OECD ones. The average assigned NRI score for OECD countries was lowered by 3.97 percent while it grew by 9.26 percent for non-OECD countries, always comparing 2001 and 2010 average values. The results shown in Table 4 also suggest a general deterioration of OECD countries macroeconomic fundamentals, like the Current Account Balance (BLNC $=-44.56$ percent), the Foreign Government Debt (FDGDP $=58.78$ percent $)$, the Public Debt $($ PDGDP $=22.58$ percent $)$ and the Unemployment $(\mathrm{UNPL}=35.59$ percent $)$. The latter results illustrate the economic turmoil and the interventionist efforts of the respective governments caused by the financial crisis of 2007 , which originated in US and was transmitted rapidly through the financial channel, thus striking first the advanced economies, which also recovered last (Didier, et.al., 2012). On the other hand, nonOECD countries escape much of the crisis backwash and present rapid improvements concerning their macroeconomic fundamentals; BLNC (294.88 percent), FDGDP (-36.81 percent), PDGDP (21.21 percent) and UNPL (-13.48 percent).

\section{[Insert Table 4 about here]}

Moreover, in order to test the equality of variable means between the two set of countries, we employ a Satterthwaite-Welch t-test which cannot reject the null hypothesis of equality only for BLNC, DFCT, and FDGDP. Overall this means that our sample consists of two well defined set of countries. On the other hand, the failure to reject the equality of means for these variables illustrates, once more, the severe effects of the economic crisis faced by those countries with stronger linkages to the international financial system, i.e. OECD countries (Berkmenet.al., 2009).

Table 5 presents the Pearson correlation coefficients between the variables approximating sovereign credit risk and cost of debt and the NRI, respectively. As expected, the assigned ratings of 
the three main agencies are highly interdependent. Cost of debt (YTM) also exhibits a strong and stable correlation with credit ratings across agencies. The NRI is very strongly and negatively correlated with credit ratings and still strongly but more loosely with YTM. The later result can be regarded as an indication that our first hypothesis holds. Furthermore, and concerning the way NRI is linked with the rest of the variables, it can be seen that NRI is strongly and positively correlated to the corruption index ${ }^{12}$.

Corruption perceptions (CRPT), and economic freedom (FRDM) are also found to be highly correlated with credit ratings and YTM. It is also striking to note that FDGDP and PDGDP are, as expected, positively correlated with credit risk ratings, albeit weakly but possess the opposite sign of correlation concerning the YTM (although for FDGDP the correlation is statistically insignificant). A possible explanation is that markets will keep financing a country's debt as long as a country remains solvent and keeps deficits under control (DFCT presents statistically significant correlation with all dependent variables).

In order to have a better insight of the way the explanatory variables correlate with response variables we break the correlation analysis in two parts, one for each set of countries and we apply a Fisher z-transformation to Pearson correlation coefficients in order to assess the significance of the difference between the two coefficients (see Table 6). The correlation between credit risk ratings and YTM is found to be much stronger for non-OECD countries (the difference is statistically significant for $\mathrm{S} \& \mathrm{P}$ ), possibly because investors and debt holders have (or think they have) a much clearer picture of OECD economies. Regarding the fundamental macroeconomic factors, OECD countries' credit

\footnotetext{
${ }^{12} \mathrm{We}$ compute the variance inflation factors of the regressors suspect to potential collinearity. The variance inflation factor of the corruption index exceeds the value of ten, which suggests further investigation. Since a high degree of collinearity destabilizes the estimated coefficients and inflates the standard errors, we re-estimate the models excluding the corruption index. The results, in general, are not supportive toward the existence of severe collinearity. Regardless the inclusion of the corruption, the standard error of the short run NRI's coefficient does not change. The standard error of the long run NRI's coefficient slightly decreases, which does not impose any econometric problem, although collinearity is probably present. Finally, the corresponding coefficients of the NRI are almost unaffected. The results are available upon request.
} 
risk ratings and YTM are mainly correlated with the Gross National Income (GNI), the Inflation (INFL) and the BLNC, while tax revenues (TAX) are interpreted rather differently by agencies and markets. More specifically TAX is negatively correlated to credit risk, but positively related to YTM. A possible explanation is that markets interpret an increase in tax revenues as a clear sign of economic distress, while agencies interpret it as an indication of adequate debt service ability. Concerning nonOECD countries, credit risk ratings and YTM are largely correlated with BLNC, DFCT and FDGDP (which in this case present a more anticipated behaviour, being positively correlated to YTM). Tax revenues are negatively correlated to both ratings and YTM (though insignificant).

[Insert Table 5 and Table 6 about here]

Finally, as shown in Table 6, the NRI is negatively correlated with all response variables for both sets of countries and exhibits a much stronger correlation for non-OECD countries presenting a first indication that our second hypothesis holds as well. Graphical depictions of these correlations are shown in Figure 1, along with overlaying bivariate regressions lines, one for each group of countries. A much steeper slope is discernible for non-OECD countries, suggesting a larger impact of NRI in this group of countries.

[Insert Figure 1 about here]

\subsection{Is a country's e-readiness inversely associated with its credit rating and cost of debt?}

In light of the methodological considerations above, our discussion will be focused on the random effects estimation that appear in Table 7. We employ a backward selection stepwise procedure with a 0.05 significance level for removal from the model. We then rerun the model including only the regressors that our selection strategy suggested as having a statistically significant impact.

As we already explained we estimate an ordered probit random effects model for credit ratings and since it is hard to directly grasp how large the effects of regressors through the ordered probit coefficients, we compute the average marginal effects and a panel linear random effects model for the cost of debt (YTM). In order to check the validity of the results of our model, we compare them 
with the corresponding results of the fixed effects model. Given the limited within-country variation of credit ratings, we added estimates only for the case of the cost of debt. According to the results, both models produce similar within panel effects and standard errors. Any discrepancies are mainly due to the inclusion of time invariant regressors. As such, we can assume that both models will perform equally well.

In order to gain more insight on the interpretation of independent variables when computing marginal effects, ratings are merged following the characterization of debt by Moody's as shown in Table $2{ }^{13}$.As we explained earlier, the rating scale, running from a high of Aaa to a low of D, comprises 21 notches and it is divided into 9 sections, from "Highest quality" to "Default"(see the columns 1 and 2 of Table 2). Sections are mapped into numerical values from 1 to 7 (see the last column of Table 2), which correspond to sections from highest (Highest quality) to lowest (sections "Very High Credit Risk", "Near Default", and "Default" are merged to a common section), respectively.

Overall, our results confirm our first hypothesis that a country's relative technological advancement on the field of information and communication, as proxied by NRI is inversely associated with credit risk ratings (as categorized above) and cost of debt (as measured from both YTM and exCoD), meaning that countries that score higher in NRI index, perform better on credit ratings and are able to borrow from financial markets at a lower cost. As we can see in Table 7, NRI seems to have only a long-run effect since all short-run coefficients regarding all regressions are insignificant. In the long-run a marginal increase in NRI increases the probability of a debt characterization of one (Highest Quality) by 0.049 for S\&P and by 0.035 for Fitch while reduces the probability of six (Very High Credit Risk) by 0.022 for S\&P and by 0.023 for Fitch. Moody's seems to place much more weight on technological diffusion since a marginal improvement in NRI would increase the probability of a debt being accredited as one of the highest quality by 0.115 and reduces

\footnotetext{
${ }^{13}$ In order to preserve space, we do not present marginal effects estimations, but calculations are available by authors upon request.
} 
the probability of $\operatorname{six}($ Very High Credit Risk) by 0.112 . With respect to the cost of debt a point increase in NRI reduces the cost of debt by around one percentage point (p.p.). ${ }^{14}$

Concerning the macroeconomic fundamentals increased GNI drives ratings and cost of debt down mainly in the short-run, except S\&P where both short and long-run coefficients are significant. Marginal effects suggest that for a marginal increase in GNI natural log, the probability of a debt characterization of one (Highest Quality) increases by 0.05 for S\&Pandby0.75 for Moody's and Fitch, while the probability of a characterization of six (Very High Credit Risk) falls by 0.025 for S\&P, by 0.072 for Moody's and by 0.049 for Fitch. In the short-run a five percent increase in GNI would improve YTM by 0.104 percentage points.

\section{[Insert Table 7 about here]}

Domestic credit to private sector is found to be significant, in the long-run, across both rating agencies and debt markets. The findings suggest that an increase to CRED (credit to private sector) improves both ratings and cost of debt. This benign effect can be justified by arguing that the higher the credit to private sector is, the more the financial resources for the private sector, which translates to higher financial development.

A growing inflation drives upwards ratings and yields to maturity in the short and in the longrun with agencies weighing more a persisting inflation. More specifically a marginal increase in inflation in the long run reduces the probability of a debt characterization of one (Highest Quality) by 0.014 while only by 0.003 for a short-run marginal increase. The change in probability for Moody's and Fitch is 0.01 and 0.002 respectively. In the long run a one percentage point increase of inflation would increase YTM by 0.5255 p.p. while in the short run the magnitude would be smaller and YTM would be increased by 0.2623 p.p.

\footnotetext{
${ }^{14}$ The last two columns of Table 7 report estimations with the EBR as the proxy of the cost of debt. As in the case of the YTM, the results support our first hypothesis. The only differences are: First, the deficit is no longer statistically significant, and second, the E.U. membership or the legal background do not seem to be appraised by the markets. Although results could be seen as a robustness check to our findings, they should be interpreted with caution due to the incongruity of the regressant.
} 
Unemployment does not seem to have a significant impact on cost of debt (both YTM and exCoD), nevertheless, findings on the regressor provide us with interesting insights concerning ratings. In the short-run, the coefficients are all positive and statistically significant, i.e. an increase in the unemployment rate deteriorates the creditworthiness of the borrower. In the long-run the results are mixed. In the cases Moody's and Fitch, the coefficients are negative and statistically significant, while in the case of S\&P the coefficient is positive and statistically insignificant.

Regarding the governmental variables, tax revenues level does not seem to have a significant impact on cost of debt although all agencies evaluate excess taxation in the long-run as an anguished effort to fulfill a country's obligations by choking the economy. On the other hand, an improvement on public revenues in the long-run has a positive impact on ratings while markets seem to penalize it by 0.06 percentage points for one p.p. increase in public revenues. Public debt also seems to be perceived differently by debt markets and rating agencies. An increase in the regressor deteriorates S\&P ratings, both in the short and long-run. In contrast, as we comment in section 3.2, debt markets do not seem alerted by such an increase. They interpret it as a sign of indefinite sustainability and of a sovereign in good standing that is being able to refinance its debt (Ito, 2011).

Of course, public debt is closely connected with deficit, which agencies and markets in the short and long-run penalize as a clear sign of economic distress that hinders government's ability to finance public debt and meet payment obligations. A one percentage point decrease in deficit would drive yields down by 0.16 p.p. in the long-run and by 0.1 p.p. in the short-run while a marginal decrease in the same regressor would increase the probability of a debt characterization of one (Highest Quality) by 0.45 for Moody's and by 0.42 for Fitch.

Turning to the external variables, current account balance has an inverse impact on credit ratings in the long-run across all agencies. A marginal improvement in current account balance in the long run increases the probability of a debt characterization of one (Highest Quality) by 0.54 for S\&P and by 0.5 for Fitch while reduces the probability of a debt characterization of six (Very High Credit Risk) by 0.24 and 0.33 respectively. 
Foreign debt as a fraction of GDP appears to worsen ratings for Moody's and Fitch in the longrun. Notwithstanding, the effect is reversed when considering S\&P ratings, a fact that at first glance appears puzzling. Further insight can be gained if one examines Table 8 and Table 9, which present results by country group. It can be easily seen that the effect is present for all rating agencies in the OECD group (Table 8), whereas for non-OECD countries the effect is reversed and the coefficient signs are as one would expect (Table 9). The difference can be attributed to the fact that emerging markets are able to sustain less debt without driving up default risk, which is reflected in ratings. OECD countries on the other hand are able to sustain much higher levels of debt without prompting a deterioration of their creditworthiness due to accrued trust by global investors. Therefore, the puzzling results on Table 7 are a mix of these two effects and the weighting differences between the agencies in the determination of ratings.

Concerning the rest of the variables under study, history of defaults seems to be penalized only by Moody's; a Eurozone membership is positively viewed across all agencies while markets decrease yields by 2.1 p.p., reflecting the widespread perception that currency unification would lead to a unification of credit risk for the country members (a perception that proved to be false). Being a member of OECD also leads to lower credit risk rating albeit markets do not seem to regard this membership as a significant determinant of the cost of debt.

The Index of Human Development is significant for Moody's since a marginal improvement in HDI would increase the probability of a debt characterization of one (Highest Quality) by 0.68 in the long-run and by 0.42 in the short-run. Corruption and business freedom have also a significant impact on ratings in the long and the short-run. A marginal improvement in Corruption Index in the long-run where the magnitude is larger would increase the probability of a debt characterization of one (Highest Quality) by 0.067 for S\&P and by 0.051 for Fitch while the probability of a debt characterization of 7 (Near Default or Default) would fall by 0.023 for S\&P and by 0.01 for Fitch. On the other hand, a marginal improvement in Business Freedom Index would increase the probability of debt characterization of one (Highest Quality) by 0.003 for S\&P, by 0.006 for Moody's 
and by 0.004 for Fitch. Markets also seem to appraise changes towards a more liberal business environment positively, mainly in the short-run since a one-point increase in Business Freedom Index would reduce the cost of debt by 0.11 p.p.

A country's legal system that originates from United Kingdom seems to be evaluated as a safety valve by all agencies (always in comparison to the French legal system which is our base) and also leads to one percentage point drop in the cost of debt, confirming that it is perceived as the safest legal system by investors. Scandinavian legal system origination seems to be evaluated differently by S\&P (riskier than French) and Moody's (safer than French) while markets seem to place their trust, not only on Anglo-Saxon legal systems, but also upon countries that their legal system has a socialistic background.

\subsection{Does a country's e-readiness have a different level of impact on its credit ratings and cost of debt depending on its development stage?}

Following the same econometric procedure ${ }^{15}$ we turn to our second set of hypotheses, which suggest that while NRI is inversely associated with credit ratings (as re-coded numerically) and cost of debt for the entirety of countries, it will have a much more severe impact on non-OECD countries' ratings and yields. Tables 8 and 9 present the regression analysis for OECD and non-OECD countries, respectively.

Overall, the results seem to lend support to our second hypothesis. Short and long-run NRI coefficients are not statistically significant for OECD countries (with the exception of Moody's were NRI enters the regression with the opposite sign in the short-run) while on the contrary, long-run NRI coefficients concerning the non-OECD countries are statistically significant across all agencies, presenting an inverse correlation with credit ratings.

Additionally, debt markets seem to put also emphasis to the technological performance of a non-OECD country by reducing their cost of debt by 1.1 percentage points for every additional point in the NRI they manage to reach. The findings allow us to suggest that concerning the non-OECD

\footnotetext{
${ }^{15}$ We do not attempt to estimate marginal effects on the subsamples due to limited variation
} 
countries, agencies and markets distinguish the continuing and long-lasting efforts a country makes to advance its technological status, as an important determinant of its ability to service its debt in the future.

\section{[Insert Table 8 about here]}

Regarding OECD countries, all agencies seem to take into account mainly the current account balance in the long-run. It is worth mentioning that in the short-run, Moody's appraise a decrease in deficit as a sign of economic distress and as an effort to cut down consumption. It is also interesting that for this group of countries and in the long-run, increases on average foreign debt signal a growing trust by the investors and drive credit ratings downwards while the short-run deviation from the average enters positively and significantly the S\&P model, indicating the difference between longrun trust and short-run increased indebtedness. On the other hand, public debt in the short and the long-run leads to a deterioration of ratings for S\&P and Moody's. Inflation also leads to a deterioration of credit ratings on both short and long-run and across all agencies while unemployment's short-run deviation from the average enters positively and significantly only the S\&P estimation. Eurozone membership and legal system originating from UK or having a socialistic background seem to have a significant inverse impact on ratings driving them downwards. On the other hand, debt markets seem to employ a rather limited number of determinants concerning the OECD cluster of countries and penalize a short-run expansionary credit policy, a short and long-run raise in inflation and a long-run raise in tax revenues considering such a raise as signal of unnecessary growth of public expenses that need to be financed and abstract resources from the real economy.

When attributing ratings to non-OECD countries, agencies, except NRI, seem to put emphasis on average current account balance and long-run fiscal balance (DFCT). In contrast to OECD countries, average foreign debt in non-OECD countries is a predictor of rating deterioration. Inflation in the long run and unemployment in the short run are also significant determinants of non-OECD credit risk ratings. 
Concerning the cost of debt of non-OECD countries, in the case of the YTMs, no significant random effects were found to exist, probably because of the small sample that we had in our disposal and therefore no panel random effects analysis was performed. Instead, we carried out a pooled panel regression without breaking our variables in averages and deviations from the average. In the case of the exCoD, where we incorporate data from the JP Morgan index, the results fail to lend support to our second hypothesis and NRI fails to enter the regression. The random effects specification cannot be considered as successful since none of the mean group centered variables enter the regression (see the $5^{\text {th }}$ column of Table 9)

The findings suggest that apart from NRI, current account and fiscal balance, along with inflation, taxation and public debt are the main predictors of the cost of debt that non-OECD countries face. It is worth mentioning that taxation enters the cost of debt model with a negative sign meaning that for this group of countries markets consider increased taxes as a reassuring sign that the country will continue to meet its debt obligations. Moreover, and contrary to the findings concerning the OECD cluster of countries, increased public debt to GDP ratio impels a rise of interest rates. Prior default is also penalized by markets while a socialistic or an Anglo-Saxon background of the country's legal system enhances investor's trust to a country's creditworthiness.

[Insert Table 9 about here]

\subsection{Robustness tests}

\subsubsection{Years of crisis}

The burst of the economic crisis towards the end of 2007 and the deterioration of ratings and sharp increases in cost of debt that followed, necessitate the investigation of the stability of our estimated models before and after the beginning of the economic crisis. Therefore, we divide our sample in two periods; 2001-2006 and 2007-2010 and we conduct a Chow test which we present at the bottom ofTable10. Our null hypothesis, that our coefficients are constant across the two periods is strongly rejected for all our response variables indicating a possible break in time, around 2007 which coincides with the burst of the economic crisis. 
In order to take a closer look since Chow test suggests a break, we re-estimate our models separately for the two aforementioned periods and present the resultsinTable10. Interestingly, NRI in the long run is a significant predictor during the crisis years (2007-2010) for Moody's and Fitch, while for S\&P the coefficient is very similar to this of the antecedent period albeit no longer significant. So, our findings suggest that our first hypothesis is quite robust despite time breaks and that NRI is an important predictor of credit ratings before and after the beginning of the economic crisis that could possibly have altered the determinants.

\section{[Insert Table10 about here]}

Concerning the other variables, it is striking that in relation to the current account balance and the crisis years, the long-run coefficients reentering the models with a negative sign and the short-run with the opposite, indicating that for the period 2007-2010, agencies prize economic policies that aim in reducing deficits or enlarging surpluses but in the short-run consider balance deficit shortenings not a result of economic growth but as a result of economic distress that cuts down consumption. Other important differences that can be spotted between the two periods is the positive appraisal by agencies of the domestic credit to the private sector during crisis years probably as a reaction to recession and the significant effect of unemployment during 2007-2010 not only in the long but also in the short run.

Regarding the debt markets, there is no evidence that a discernible changing context of determinants exist before and after the time break and NRI fails to enter the estimation model as a significant predictor in both periods.

\subsubsection{Other measures of ICT diffusion}

In order to check the validity of our results in case of alternative measures of ICT diffusion, we employ as regressors and alternative proxies of the e-readiness concept the EIU E-Readiness Index and the E-Government Readiness Index, presented in section 3.1. We re-estimate equations (4) and (5) using the same set of control variables across all regression in Table 7 . The results are presented in Table 11. Both the EIU E-Readiness Index (EIU INDEX) and the E-Government Readiness Index 
(E-GOV INDEX) are insignificant at the 5\% statistical significance level, except the cases of RTGM and YTM, where the E-Government Readiness Index is significant at 5\% and 1\%, respectively. The estimations using the EIU E-Readiness Index and the E-Government Readiness Index are similar to the equivalent estimations using NRI. The only exception is the case of the E-Government Readiness Index, where in one case its regression coefficient has the opposite sign than that expected from our baseline regressions findings. Up to our knowledge, there are two potential explanations of the above finding. First, E-Government Readiness Index shows the level governments are aware and benefiting from ICT, and as such it does not reflect the concept of e-readiness to its entirety. Second, data for the index under consideration are available only for 2003, 2004, 2005, 2008, and 2010, i.e. half of our sample size.

[Insert Table 11 about here]

\subsubsection{Other overall measures of technology}

In the current section, we test if alternative overall measures of technology provide some more insights than the e-readiness concept proxied by the NRI. Toward this end, we construct two such measures namely: Patents per Inhabitant (PTNTS) and Internet Users per Inhabitant (INTUSRS). The first is constructed by adding the patents granted to each country by the European Patent Office and the United States Patent Office and dividing the sum by the country's population. The second is constructed by dividing each country's internet users again by its population. We test the NRI performance, after explicitly controlling for technological diffusion, by adding both variables as additional regressors in our baseline regressions. The results are reported in Table 12.

[Insert Table 12 about here]

In the case of credit ratings, NRI remains statistically significant with comparable to the baseline regressions effects (see Table 7) independently if we introduce PTNTS or INTUSRS. Instead, in the case of the cost of debt, NRI is no longer significant, although both the sign and the effect remain almost the same compared to those of the baseline regression(see Table 7). Moreover, if we substitute the regressant with the second measure of the cost of debt (exCoD) the NRI becomes 
again statistically significant with the correct sign when introduced in the regression together with PTNTS. Patents per Inhabitant is insignificant in all cases but Internet users per Inhabitant can be seen as having as being interpreted similarly to NRI by the markets (but not agencies) because when introduced to the regressions, NRI becomes insignificant while INTUSRS exhibits statistical significance and the expected sign.

\subsubsection{Channels of ICT impact}

In order to further investigate the channels through which ICT affects the cost and rating of sovereign debt, we introduce in our model additional economic variables, such as the GDP growth (GDPG) and the natural log of the output per worker according to International Labour Office estimates (LPROD). The aforementioned variables allow us to explicitly control for the effect of economic growth and labour productivity, respectively. The results are shown in Table 13.

[Insert Table 13 about here]

In the short term, GDP growth negatively affects both the credit ratings and the cost of debt (YTM and exCoD). In the long term, the effect of GDP growth is still negative in all cases except the ratings published by $\mathrm{S} \& \mathrm{P}$. The effect is statistically significant in the short term (long term) in the case of the credit ratings (cost of debt). The latter indicates that markets focus more on the long run growth (see Afonso, 2011, for similar results). Regarding the productivity growth as proxied by the labour production, the results indicate that it has a long-term effect (Duggar, 2017). In the short term, its effect is statistical insignificant in almost all cases. In the long run, the effect is negative in all cases and statistically significant in most of them.

The NRI variable is statistically insignificant, as expected, in all cases but Moody's. The indirect nature of the e-readiness effect on ratings and debt, controlling for labour productivity and GDP growth will force NRI variable to become statistically insignificant. Otherwise it should be presumed that ICT have an impact on both cost of debt and ratings, through additional channels that have not been addressed in the current study. It is interesting though that in the only regression that GDP growth fails to enter as a significant regressant, i.e. Moody's, NRI remains statistically 
significant. Thus, ICT may have a more direct impact on ratings probably as a predictor of future growth, making concurrent growth rates less relevant to the assigned ratings. Overall though, findings lend support to the conjecture that the main channels through ICT impacts debt markets are labour productivity and growth.

\section{Conclusions}

In this paper we investigate the role played by ICT technologies in the assigning process of credit risk ratings by the three market dominating agencies (S\&P, Moody's and Fitch) and the way debt markets appraise a country's level of ICT diffusion. In order to test our hypotheses, we use ratings and yields to maturity of 10-year zero-coupon sovereign benchmark bonds along with a balanced panel data set of economic, financial and qualitative regressors suggested by previous literature.

Overall our results confirm our first hypothesis that a country's e-readiness status in significantly associated with credit risk ratings and cost of debt. The findings corroborate the view that ICT, of which e-readiness is a metric of usage and diffusion have a long-run impact on important determinants of economic and financial policies like cost of debt and credit ratings that can possibly hinder or foster a country's prosperity. Based on our robustness checks, it could be suggested that since the NRI variable loses significance when economic growth and labour productivity enter the model, these are the main channels through which ICT impacts debt markets. Moreover, the results lend support to our second hypothesis as well, indicating that in developing countries, ICT play a much more crucial role in the assignment of credit rating and the cost of debt.

In line with the findings of $\mathrm{Vu}$ (2011), Jorgenson and $\mathrm{Vu}$ (2010) and Waverman et.al., (2005) that ICT continue to expand their contribution to developing countries growth, our results provide an indirect indication that by putting more emphasis on e-readiness, developing countries can improve their prospects with rating agencies and debt markets.

Our findings also suggest that in the short run the most important determinants of credit risk ratings and cost of debt are GNI and unemployment while in the long run domestic credit to private sector, current account balance, public revenues and taxation seem to play a more important role. 
Inflation, budget deficit or surplus and public debt have an impact on the response variables in the short and the long-run. Being a member of Eurozone, a legal system that originates from AngloSaxon or socialistic legal traditions and no history of default are also found to be appraised positively by agencies and markets. The rest of the robustness checks suggest that e-readiness keeps on having a significant impact on ratings before and during crisis years.

A straightforward policy implication can be derived from our findings; investing in ICTs and their diffusion will not only contribute to growth directly and through spillovers but will ease, especially for non-OECD countries, access to debt markets.

One limitation of our research is that ICT may be an endogenous variable, because shocks to the cost of public debt may imply less public and private investment in ICT. Towards this end, additional research is needed to address the theoretical underpinnings of the link between ICT, sovereign ratings and cost of debt. Understanding the economic channels through these effects are running, may lead to a more comprehensive random effects econometric model, which deals with endogeneity issues. Finally, it should be acknowledged that we only provide a brief discussion on other metrics of ICT diffusion and mainly in a robustness context. Therefore, in order to gain additional insights much further work should be done exploring the impact of other such measures on debt markets and credit ratings.

\section{References}

Afonso, A., Gomes, P. and Rother, P. (2011). Short and long-run determinants of sovereign debt credit ratings. International Journal of Finance \& Economics, 16(1), pp.1-15.

Allison, P. (2009). Fixed Effects Regression Models. SAGE Publications.

Baek, I.-M., Bandopadhyaya, A. and Du, C. (2005). Determinants of market-assessed sovereign risk: Economic fundamentals or market risk appetite? Journal of International Money and Finance, 24(4), pp. 533-548 
Bartels, B. (2009). Beyond Fixed versus Random Effects: A Framework for Improving Substantive and Statistical Analysis of Panel, Time-Series Cross-Sectional, and Multilevel Data, Society for Political Methodology.

Bell A. and Jones K., (2015). Explaining Fixed Effects: Random Effects Modeling of Time-Series Cross-Sectional and Panel Data. Political Science Research and Methods 3(1), pp.133 - 153

Bennell, J., Crobbe D., Thomas S., and Gwilym O. (2006). Modelling sovereign credit ratings: Neural networks versus ordered probit. Expert Systems with Applications, 30(3), pp. 415-425

Berkmen, P., Gelos, G., Rennhack, R., Walsh, J., (2009), The Global Financial Crisis: Explaining Cross - Country Differences in the Output Impact, IMF Working Paper, WP/09/280

Bhatia, A. (2002) Sovereign credit ratings methodology: an evaluation. IMF Working Paper $\mathrm{WP} / 02 / 170$.

Bhatta B., Marshall A. and Thapa C., (2018). Foreign bias in bond portfolio investments: the role of economic and non-economic factors and the impact of the global financial and sovereign debt crises, The European Journal of Finance,24(7-8), pp. 654 - 681

Bissoondoyal-Bheenick, E. (2005). An analysis of determinants of sovereign ratings. Global Finance Journal 15(3), pp. 251-280.

Bissoondoyal-Bheenick, E., Brooks, R., and Yip, A. (2006). Determinants of sovereign ratings: A comparison of case-based reasoning and ordered probit approaches. Global Finance Journal, 17(1), pp. $136-154$.

Brynjolffsson, E. and Hitt, L. (2003). Computing Productivity: Firm-Level Evidence. The Review of Economics and Statistics, 85(4), pp. 793 -808.

Cantor R., and Packer, F. (1996). Determinants and impact of sovereign credit ratings. Economic Policy Review, 2 (2), pp. 37 - 53 Choi, C. (2003). Does the Internet stimulate inward foreign direct investment? Journal of Policy Modeling, 25(4), pp. 319-326.

Crandall, R., Lehr, W. and Litan, R. (2007). The effects of Broadband deployment on output and employment: A cross-sectional analysis of US data. Issues in Economic Policy, 6(6), pp. 1-34. 
Cruces, B. J. J. and Trebesch, C. (2013). Sovereign Defaults: The Price of Haircuts Source. American Economic Journal: Macroeconomics, 5(3), pp. 85-117.

Didier, T., Hevia, C., Schmukler, S. (2012). How resilient and countercyclical were emerging economies during the global financial crisis? Journal of International Money and Finance, pp. 1-26. Duggar, E. (2017). Low Productivity Growth and Sovereign Debt Sustainability. Peterson Institute for International Economics, Washington DC.

Economist Intelligence Unit (2001-2009). E-readiness rankings, New York: Economic Intelligence Unit.

Feder, G. and Uy, L. V (1985). The determinants of international creditworthiness and their policy implications. Journal of Policy Modeling, 7(1), pp. 133-156

Ferri, G., Liu, L. G., and Stiglitz, J. E. (1999). Are credit ratings pro- cyclical? Evidence from East Asian Countries. Economic Notes, 28(3), pp. 335-355

Frechette, G., (2001). sg158: Random-effects ordered probit. STATA Technical Bulletin 59, pp. 2327.

Geiger, T., and Mia, I. (2009). Mobile Telephony: A critical Enabler of Networked Readiness? In: S. Dutta and I. Mia, eds., The Global Information Technology Report 2008-2009, Geneva: World Economic Forum.

Gordon, R. (2000). Does the "New Economy" Measure up to the Great Inventions of the Past? The Journal of Economic Perspectives, 14(4), pp. 49 -74.

Greene W., (2012). Econometric Analysis, 7th ed. Harlow: Pearson.

Grigorovici, D. M., Schement, J. R. and Taylor, R. D., (2004). Weighing the intangible: Towards a framework for information society indices. In: E. Bohlin, S. Levin, N. Sung, and C-H. Yoon, eds, Global Economy and Digital Society, 1st edition, Elsevier.

Hanafizadeh, P., Hanafizadeh, M. and Khodabakhshi, M. (2009). Taxonomy of e-readiness assessment measures. International Journal of Information Management, 29, pp. 189 - 195. 
Haque, N., Kumar, M., Mark, N. and Mathieson, D. (1996). The economic content of indicators of developing country creditworthiness, IMF Staff Papers 43, pp. 688-724.

Heeks R. (2001), Understanding e-Governance for Development, Working Paper No 11, Institute for Development, Policy and Management, University of Manchester.

Holt, L. and Jamison, M. (2009). Broadband and contributions to economic growth: Lessons from the US experience. Telecommunications Policy 33, pp. 575-581.

House, R. J., Hanges, P.J., Javidan, M., Dorfman, P.W. and Gupta, V. (2004). Culture, leadership, and organization: The GLOBE study of 62 societies. Sage Publications.

Indjikian, R. and Siegel, D.S. (2005). The Impact of Investment in IT on Economic Performance: Implications for Developing Countries. World Development 33, pp. 681-700.

Ito. T., (2011). Sustainability of Japanese Sovereign Debt, in Ito, T. and F. Parulian (eds.), Assessment on the Impact of Stimulus, Fiscal Transparency and Fiscal Risk. ERIA Research Project Report 201001, pp.29-76.

Jalava, J. and Pohjola, M. (2002). Economic growth in the New Economy: evidence from advanced economies. Information Economics and Policy 14, pp. 189-210.

Jorgenson, D. W. and Stiroh, K. (2000). Raising the speed limit: US economic growth in the information age. Brookings papers on economic activity, 1, pp. 125-210.

Jorgenson, D. W. and Vu, K. M. (2010). Potential growth of the world economy. Journal of Policy Modeling, 32(5), pp.615-631.

Keef, S.P., Khaled, M. Zhu, H. (2009). The dynamics of the Monday effect in international stock indices, International Review of Financial Analysis, 18(3), pp. 125-133,

La Porta, R., Lopez-de-Silanes F., Schleifer, A. and Vishny, R. (1999). The Quality of Government. Journal of Law, Economics and Organization, 15(1), pp.222-279

Lemmen, J. and Goodhart, C., (1999). Credit risks and European government bond markets: a panel data econometric analysis. Eastern Economic Journal, 25, pp. 77-107 
Lucas, H. and Sylla, R. (2003). The global impact of the Internet: Widening the economic gap between wealthy and poor nations? Prometheus, 21(1), pp. 1-22.

Luo, Y., \& Bu, J. (2016). How valuable is information and communication technology? A study of emerging economy enterprises. Journal of World Business,51(2), pp. 200-211.

Maltritz, D. (2012). Determinants of sovereign yield spreads in the Eurozone: A Bayesian approach. Journal of International Money and Finance. 31(3), pp. 657-672.

Mellios, C., Paget-Blanc, E., 2006. Which factors determine sovereign credit ratings? The European Journal of Finance 12, 361-377.

Morsink, J., \&Haacker, M. M. (2002). You Say You Want A Revolution: Information Technology and Growth (No. 2-70). International Monetary Fund.

Mundlak, Y. (1978). On the Pooling of Time-series and Cross-section Data. Econometrica46 pp.6985.

Oliner, S. D. and Sichel, D. E. (2000). The Resurgence of Growth in the Late 1990s: Is Information Technology the Story? Journal of Economic Perspectives, 14(4), pp. 3-22.

Papaioannou, S. K. and Dimelis, S. P. (2007). Information Technology as a Factor of Economic Development: Evidence from Developed and Developing Countries. Economics of Innovation and New Technology, 16(3), pp. 179-194.

Pohjola, M. (2001). Information Technology and Economic Growth: A Cross-Country Analysis. Emergo. Journal of Transforming Economies and Societies, 8(2), pp. 20-33.

Remolona, E., Scatinga, M. and Wu, E. (2007). Interpreting sovereign spreads. BIS Quaerterly Review, (March), pp. 27-39.

Reusens, P. and Croux, C. (2017). Sovereign credit rating determinants: A comparison before and after the European debt crisis. Journal of Banking and Finance, 77, pp. 108-121.

Schreyer, P. (2000). The Contribution of Information and Communication Technology to Output Growth: A study to the G7 countries. OECD Science, Technology and Industry Working Papers, 2000/2, OECD Publishing. 
Seo, H.J., Lee, Y. S. and Oh, J. H. (2009). Does ICT investment widen the growth gap? Telecommunications Policy, 33(8), pp.422-431.

Solow R, (1957). Technical Change and the aggregate production Function. Review of Economics and Statistics, 39 (3), pp. $312-320$.

Stiroh, K.J. (2003). Economic Impacts of Information Technology. In: Encyclopedia of Information Systems, New York: Elsevier, pp. 1-14.

Ugur, M. and Mitra, A. (2017). Technology Adoption and Employment in Less Developed Countries: A Mixed-Method Systematic Review. World Development, 96, pp. 1-18.

UN, (2005) World Summit Outcome. http://www.un.org/womenwatch/ods/A-RES-60-1-E.pdf.

Vu, K. M. (2011). ICT as a source of economic growth in the information age: Empirical evidence from the 1996-2005 period. Telecommunications Policy, 35(4), pp. 357-372.

Waverman, L., Meschi, M. and Fuss, M. (2005). The impact of telecoms on economic growth in developing countries. The Vodafone Policy Paper, 2, pp.10-23.

Wooldridge, J.M. (2002). Econometric Analysis of Cross Section and Panel Data. MIT Press Cambridge

Wu, W.W., Lan, L.W., and Lee, Y.T. (2012). Exploring the critical pillars and causal relations within the NRI: An innovative approach. European Journal of Operational Research, 218, pp.230-238.

Yi, M. H. and Choi, C. (2005). The effect of the Internet on inflation: Panel data evidence. Journal of Policy Modeling, 27(7), pp. 885-889. 


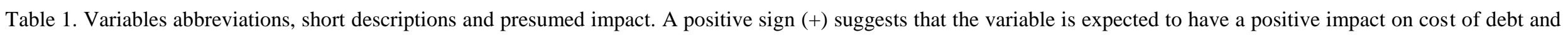
credit risk ranking while a negative sign (-) suggest a negative impact according to literature and empirical findings.

\begin{tabular}{|c|c|c|c|}
\hline Variable & Description & Source & Effect \\
\hline $\begin{array}{l}\text { RTGSP, RTGM, } \\
\text { RTGF }\end{array}$ & $\begin{array}{l}\text { Sovereign credit ratings assigned by S\&P, Moody’s and Fitch accordingly. The qualitative letter rating is transformed linearly to numerical equivalents with number } 1 \text { representing the } \\
\text { highest score (AAA for S\&P and Fitch, Aaa for Moody's) and number } 21 \text { the lowest (D for S\&P and Fitch, C for Moody's), see also Table } 2\end{array}$ & S\&P, Moody’s, Fitch & \\
\hline YTM/-EMBI & The yield to maturity of a 10-year zero coupon benchmark bond multiplied by 100. If none available, then JP Morgan Emerging Markets Bond Index (Global) was used. & DataStream & \\
\hline NRI & $\begin{array}{l}\text { Networked Readiness Index: It is published annually by World Economic Forum and INSEAD and ranges from } 1 \text { to } 10 \text { with higher values indicating a higher diffusion and use of } \\
\text { ICT's. }\end{array}$ & $\begin{array}{l}\text { The Global Information } \\
\text { Reports }\end{array}$ & ? \\
\hline EIU INDEX & $\begin{array}{l}\text { Economist Intelligence Unit E-Readiness Index: It is published annually by Economist and IBM and ranges from } 1 \text { to } 10 \text { with higher values indicating a higher diffusion and use of } \\
\text { ICT's. }\end{array}$ & Economist & $?$ \\
\hline EGOV INDEX & $\begin{array}{l}\text { E - Government Development Index. It is published irregularly by the United Nations and ranges from } 0 \text { to } 1 \text { with higher values indicating a higher diffusion and use of ICT's. Data } \\
\text { are available for } 2004,2005,2008 \text {, and } 2010 \text {. }\end{array}$ & United Nations & ? \\
\hline BLNC & $\begin{array}{l}\text { Current Account balance: The sum of trade balance (goods and services exports less imports), net income from abroad and net current transfers. A positive current account balance } \\
\text { reflects a country's net investment abroad while a negative current account balance reflects the foreign net investment to the country. Expressed as a fraction of GDP. }\end{array}$ & World Bank & $(+/-)$ \\
\hline CRED & $\begin{array}{l}\text { Domestic credit to private sector: Refers to financial resources provided to the private sector by financial corporations, such as through loans, purchases of non-equity securities, and } \\
\text { trade credits and other accounts receivable, that establish a claim for repayment. Expressed as a fraction of GDP. }\end{array}$ & World Bank & $(+/-)$ \\
\hline CRPT & $\begin{array}{l}\text { Corruption Perception Index: The CPI scores and ranks countries based on how corrupt a country's public sector is perceived to be. It is a composite index, a combination of surveys } \\
\text { and assessments of corruption and is published annually, ranging from zero (highly corrupt) to ten (highly clean). }\end{array}$ & $\begin{array}{l}\text { Transparency } \\
\text { International }\end{array}$ & $(-)$ \\
\hline DFCT & Cash Surplus or deficit: Revenue (including grants) minus expense, minus net acquisition of nonfinancial assets. Expressed as a fraction of GDP. & $\begin{array}{l}\text { World Bank, } \\
\text { DataStream }\end{array}$ & $(-)$ \\
\hline DFLT75/DFLT95 & $\begin{array}{l}\text { The two dummy variables correspond to a default to any of the three types of default identified by S\&P, local currency debt, foreign currency bond debt and foreign currency bank } \\
\text { debt. If any of these kinds of default took place during 1975-2010 then the dummy variable DFLT75 takes the value of one while if it took place during } 1995-2010 \text { then the dummy } \\
\text { variable DFLT95 takes the value of one. }\end{array}$ & S\&P & $(+)$ \\
\hline EURO/OECD & The two dummy variables correspond to a membership to Eurozone and OECD respectively; a value of one means that a country is a member of the Eurozone or OECD. & Eurozone, OECD & $(-)$ \\
\hline FDGDP & $\begin{array}{l}\text { Foreign Government Debt: The portion of a government's debt that was borrowed from foreign lenders including commercial banks, governments or international financial institutions. } \\
\text { Expressed as a fraction of GDP. }\end{array}$ & $\begin{array}{l}\text { Euromonitor, } \\
\text { Own calculations }\end{array}$ & $(+)$ \\
\hline FRDM & $\begin{array}{l}\text { Index of Economic Freedom: It's a composite index that mainly reflects the level of enforcement of the rights of individuals to accumulate private property, to start, operate and close } \\
\text { a business and to transfer capital resources through a country's border. The Index takes values from } 1-100 \text { with higher values indicating a higher rank of economic freedom. }\end{array}$ & $\begin{array}{l}\text { The Heritage } \\
\text { Foundation }\end{array}$ & $(-)$ \\
\hline GNI & $\begin{array}{l}\text { Gross National Income: It is the aggregate value of the gross balances of primary incomes for all sectors and is defined as GDP plus compensation of employees' receivable from } \\
\text { abroad plus property income receivable from abroad plus taxes less subsidies on production receivable from abroad less compensation of employees payable abroad less property } \\
\text { income payable abroad and less taxes plus subsidies on production payable abroad. Expressed in constant US\$ (2013). Natural log transformed. }\end{array}$ & World Bank & $(-)$ \\
\hline GDPG & $\begin{array}{l}\text { Gross Domestic Product Growth: GDP is the sum of gross value added by all resident producers in the economy plus any product taxes and minus any subsidies not included in the } \\
\text { value of the products. It is expressed as a percentage that shows the rate of change in a country's GDP from one year to the next. }\end{array}$ & World Bank & $(-)$ \\
\hline HDI & $\begin{array}{l}\text { United Nation's Human Development Index: It is a composite statistic of life expectancy, education and standard of living published annually. It can take any value from } 0 \text { (least } \\
\text { developed) to } 1 \text { (most developed). }\end{array}$ & United Nations & $(-)$ \\
\hline INFL & Inflation: As measured by the consumer price index. & World Bank & $(+)$ \\
\hline INTUSRS & Internet Users Per Inhabitant. Number of internet users as a fraction of a country's population & $\begin{array}{l}\text { International } \\
\text { Telecommunications } \\
\text { Union }\end{array}$ & ? \\
\hline LGL ( $\left.x^{\prime}\right)$ & $\begin{array}{l}\text { The five dummy variables show the origin of the legal system. LGLFRC, LGLGRM, LGLSKN, LGLSOC and LGLUK stand for a legal system that originates from France, Germany, } \\
\text { Scandinavia, Socialist States and United Kingdom. }\end{array}$ & La Porta et.al., (1999) & $(+/-)$ \\
\hline LPROD & Labour Productivity: As measured by the output per worker expressed in constant 2010 US\$. Log transformed. & $\begin{array}{l}\text { International Labour } \\
\text { Organisation }\end{array}$ & $(-)$ \\
\hline PDGDP & $\begin{array}{l}\text { Public Debt: Total debt owned by any level of the Government. It consists of all liabilities that require payment or payments of interest and/or principal by the debtor to the creditor at } \\
\text { a date or dates in the future. Expressed as a fraction of GDP. }\end{array}$ & IMF & $(+)$ \\
\hline PTNTS & Patents per Inhabitant. Sum of patents granted to each country by the European Patent Office and the United States Patent Office. Expressed as a fraction of the population. & USPTO/EPO & $(-)$ \\
\hline REV & Government Revenues: A sum of taxes, subsidies, social contributions, grants receivable and other current and capital transfers. Expressed as a fraction of GDP. & IMF & $(-)$ \\
\hline TAX & $\begin{array}{l}\text { Tax revenues: It refers to compulsory transfers to the central government for public purposes. Certain compulsory transfers such as fines, penalties, and most social security contributions } \\
\text { are excluded. Expressed as a fraction of GDP. }\end{array}$ & $\begin{array}{l}\text { World Bank, } \\
\text { DataStream }\end{array}$ & $(+/-)$ \\
\hline UNPL & Unemployment: Refers to the share of the labour force that is without work but available for and seeking employment. Expressed as a fraction of total labour force. & World Bank & $(+)$ \\
\hline
\end{tabular}


Table 2.Linear transformation of assigned ratings by S\&P, Moody's and Fitch, adopted from Afonso et.al. (2011) and modified accordingly by authors.

\begin{tabular}{|c|c|c|c|c|c|c|c|}
\hline & & & & TING & & & \\
\hline & $\begin{array}{l}\text { erization of issuer and debt by } \\
\text { Moody's }\end{array}$ & $\mathbf{S} \& \mathbf{P}$ & Moody's & Fitch & $\begin{array}{r}\text { Nu } \\
\text { Trans }\end{array}$ & $\begin{array}{l}\text { cal } \\
\text { lation }\end{array}$ & $\begin{array}{c}\text { Effects } \\
\text { Transformation }\end{array}$ \\
\hline & Highest Quality & $\mathrm{AAA}$ & Aaa & AAA & 1 & 1 & 1 \\
\hline & & AA+ & Aa1 & $\mathrm{AA}+$ & 2 & 2 & \\
\hline 됭 & High Quality & AA & $\mathrm{Aa} 2$ & AA & 3 & 3 & 2 \\
\hline 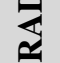 & & AA- & Aa3 & AA- & 4 & 4 & \\
\hline जै & & $\mathrm{A}+$ & A1 & $\mathrm{A}+$ & 5 & 5 & \\
\hline$\underline{Z}$ & Strong Payment Capacity & A & A2 & A & 6 & 6 & 3 \\
\hline 5 & & A- & $\mathrm{A} 3$ & A- & 7 & 7 & \\
\hline 忞 & & $\mathrm{BBB}+$ & Baa1 & $\mathrm{BBB}+$ & 8 & 8 & \\
\hline & Adequate Payment Capacity & BBB & Baa2 & BBB & 9 & 9 & 4 \\
\hline & & BBB- & Baa3 & BBB- & 10 & 10 & \\
\hline & & $\mathrm{BB}+$ & $\mathrm{Ba} 1$ & $\mathrm{BB}+$ & 11 & 11 & \\
\hline & $\begin{array}{l}\text { Likely to fulfil obligations, } \\
\text { uncertainty }\end{array}$ & $\mathrm{BB}$ & $\mathrm{Ba} 2$ & BB & 12 & 12 & 5 \\
\hline $\bar{z}$ & & BB- & $\mathrm{Ba} 3$ & BB- & 13 & 13 & \\
\hline สื & & $\mathrm{B}+$ & B1 & $\mathrm{B}+$ & 14 & 14 & \\
\hline 딘 & High Credit Risk & $\mathrm{B}$ & B2 & B & 15 & 15 & 6 \\
\hline Z & & $\mathrm{B}-$ & B3 & B- & 16 & 16 & \\
\hline 岁 & & $\mathrm{CCC}+$ & Caal & & & 17 & \\
\hline 8 & Very High Credit Risk & $\mathrm{CCC}$ & $\mathrm{Caa} 2$ & $\mathrm{CCC}$ & 17 & 18 & \\
\hline$\frac{r r}{n}$ & & $\mathrm{CCC}-$ & $\mathrm{Caa} 3$ & & & 19 & 7 \\
\hline & Near Default & $\mathrm{CC} \& \mathrm{C}$ & $\mathrm{Ca}$ & & & 20 & \\
\hline & Default & $\mathrm{D}$ & $\mathrm{C}$ & $\mathrm{D}$ & 21 & 21 & \\
\hline
\end{tabular}


Table 3. Country - wise statistics of the main variables.

\begin{tabular}{|c|c|c|c|c|c|c|c|c|c|c|c|c|c|c|c|c|c|c|c|c|c|c|}
\hline \multirow[b]{2}{*}{ Country } & \multicolumn{2}{|c|}{ RTGM } & \multicolumn{2}{|c|}{ YTM } & \multicolumn{2}{|c|}{ NRI } & \multicolumn{2}{|c|}{ BLNC } & \multicolumn{2}{|c|}{ CRED } & \multicolumn{2}{|c|}{ DFCT } & \multicolumn{2}{|c|}{ INFL } & \multicolumn{2}{|c|}{ PDGDP } & \multicolumn{2}{|c|}{ REV } & \multicolumn{2}{|c|}{ TAX } & \multicolumn{2}{|c|}{ UNPL } \\
\hline & Mean & $\begin{array}{l}\text { Std. } \\
\text { Dev. }\end{array}$ & Mean & $\begin{array}{l}\text { Std. } \\
\text { Dev. }\end{array}$ & Mean & $\begin{array}{l}\text { Std. } \\
\text { Dev. }\end{array}$ & Mean & $\begin{array}{l}\text { Std. } \\
\text { Dev. }\end{array}$ & Mean & $\begin{array}{l}\text { Std. } \\
\text { Dev. }\end{array}$ & Mean & $\begin{array}{l}\text { Std. } \\
\text { Dev. }\end{array}$ & Mean & $\begin{array}{l}\text { Std. } \\
\text { Dev. }\end{array}$ & Mean & $\begin{array}{c}\text { Std. } \\
\text { Dev. }\end{array}$ & Mean & $\begin{array}{l}\text { Std. } \\
\text { Dev. }\end{array}$ & Mean & $\begin{array}{l}\text { Std. } \\
\text { Dev. }\end{array}$ & Mean & $\begin{array}{c}\text { Std. } \\
\text { Dev. }\end{array}$ \\
\hline Australia & 1.4 & 0.843 & 5.457 & 0.644 & 5.112 & 0.146 & -0.049 & 0.016 & 1.110 & 0.155 & 0.002 & 0.020 & 3.006 & 0.849 & 0.137 & 0.036 & 0.351 & 0.016 & 0.237 & 0.013 & 0.054 & 0.008 \\
\hline Austria & 1.0 & 0.000 & 4.172 & 0.612 & 5.002 & 0.234 & 0.025 & 0.015 & 1.137 & 0.081 & -0.021 & 0.012 & 1.934 & 0.747 & 0.655 & 0.033 & 0.488 & 0.011 & 0.201 & 0.010 & 0.044 & 0.005 \\
\hline Azerbaijan & 11.8 & 0.919 & & & 3.545 & 0.231 & 0.060 & 0.235 & 0.120 & 0.046 & -0.029 & 0.023 & 7.577 & 6.596 & 0.151 & 0.064 & 0.318 & 0.103 & 0.160 & 0.016 & 0.072 & 0.011 \\
\hline Belgium & 2.0 & 0.000 & 4.193 & 0.623 & 4.770 & 0.211 & 0.018 & 0.020 & 0.828 & 0.104 & -0.013 & 0.018 & 2.082 & 1.135 & 0.947 & 0.069 & 0.491 & 0.008 & 0.255 & 0.008 & 0.078 & 0.007 \\
\hline Brazil & 12.9 & 1.792 & 8.560 & 3.839 & 3.879 & 0.194 & -0.006 & 0.020 & 0.400 & 0.113 & -0.024 & 0.011 & 6.688 & 3.166 & 0.692 & 0.050 & 0.344 & 0.006 & 0.159 & 0.007 & 0.085 & 0.010 \\
\hline Bulgaria & 11.5 & 1.900 & 5.931 & 1.306 & 3.478 & 0.279 & -0.109 & 0.089 & 0.466 & 0.231 & 0.011 & 0.022 & 5.992 & 3.137 & 0.326 & 0.189 & 0.365 & 0.017 & 0.204 & 0.025 & 0.112 & 0.048 \\
\hline Canada & 1.1 & 0.316 & 4.299 & 0.824 & 5.273 & 0.140 & 0.006 & 0.020 & 1.576 & 0.259 & 0.007 & 0.014 & 2.020 & 0.673 & 0.760 & 0.065 & 0.404 & 0.010 & 0.134 & 0.008 & 0.071 & 0.008 \\
\hline Colombia & 11.7 & 0.483 & 11.318 & 3.084 & 3.559 & 0.256 & -0.018 & 0.008 & 0.323 & 0.070 & -0.047 & 0.023 & 5.572 & 1.685 & 0.385 & 0.048 & 0.259 & 0.010 & 0.117 & 0.011 & 0.124 & 0.014 \\
\hline Costa Rica & 11.0 & 0.000 & 7.065 & 1.153 & 3.727 & 0.264 & -0.049 & 0.019 & 0.384 & 0.083 & -0.011 & 0.016 & 10.371 & 2.554 & 0.340 & 0.063 & 0.142 & 0.008 & 0.093 & 0.065 & 0.063 & 0.010 \\
\hline Croatia & 10.0 & 0.000 & 4.971 & 0.748 & 3.773 & 0.250 & -0.055 & 0.021 & 0.549 & 0.111 & -0.027 & 0.012 & 2.815 & 1.424 & 0.356 & 0.034 & 0.391 & 0.006 & 0.202 & 0.009 & 0.126 & 0.036 \\
\hline Czech & 5.6 & 1.265 & 4.532 & 1.072 & 4.248 & 0.226 & -0.038 & 0.017 & 0.408 & 0.093 & -0.039 & 0.016 & 2.553 & 1.824 & 0.294 & 0.038 & 0.398 & 0.014 & 0.145 & 0.008 & 0.070 & 0.013 \\
\hline Denmark & 1.0 & 0.000 & 4.156 & 0.672 & 5.516 & 0.238 & 0.031 & 0.011 & 1.814 & 0.316 & 0.018 & 0.030 & 2.046 & 0.635 & 0.473 & 0.087 & 0.555 & 0.012 & 0.322 & 0.024 & 0.049 & 0.012 \\
\hline Egypt & 11.0 & 0.000 & 5.067 & 1.886 & 3.490 & 0.260 & 0.010 & 0.025 & 0.475 & 0.080 & -0.064 & 0.009 & 8.396 & 4.998 & 0.875 & 0.127 & 0.264 & 0.014 & 0.144 & 0.010 & 0.099 & 0.009 \\
\hline El Salvador & 10.1 & 0.316 & 7.369 & 1.347 & 3.470 & 0.221 & -0.038 & 0.019 & 0.420 & 0.011 & -0.029 & 0.021 & 3.444 & 1.827 & 0.402 & 0.052 & 0.158 & 0.010 & 0.124 & 0.014 & 0.068 & 0.006 \\
\hline Estonia & 5.6 & 1.265 & & & 4.793 & 0.268 & -0.083 & 0.068 & 0.741 & 0.245 & 0.009 & 0.017 & 4.207 & 2.905 & 0.052 & 0.011 & 0.382 & 0.040 & 0.161 & 0.006 & 0.097 & 0.039 \\
\hline Finland & 1.0 & 0.000 & 4.069 & 0.654 & 5.521 & 0.232 & 0.048 & 0.028 & 0.756 & 0.139 & 0.030 & 0.029 & 1.541 & 1.229 & 0.415 & 0.044 & 0.530 & 0.003 & 0.217 & 0.013 & 0.082 & 0.010 \\
\hline France & 1.0 & 0.000 & 4.088 & 0.610 & 4.911 & 0.190 & -0.003 & 0.012 & 0.984 & 0.107 & -0.037 & 0.019 & 1.713 & 0.693 & 0.669 & 0.081 & 0.498 & 0.005 & 0.219 & 0.009 & 0.087 & 0.006 \\
\hline Germany & 1.0 & 0.000 & 3.983 & 0.659 & 5.111 & 0.137 & 0.046 & 0.024 & 1.123 & 0.045 & -0.018 & 0.009 & 1.562 & 0.657 & 0.676 & 0.067 & 0.442 & 0.006 & 0.112 & 0.004 & 0.088 & 0.014 \\
\hline Ghana & 14.1 & 0.316 & & & 3.300 & 0.149 & -0.067 & 0.040 & 0.138 & 0.018 & -0.046 & 0.020 & 17.027 & 7.418 & 0.550 & 0.264 & 0.166 & 0.015 & 0.163 & 0.035 & 0.122 & 0.012 \\
\hline Greece & 5.6 & 1.265 & 4.676 & 0.745 & 3.903 & 0.112 & -0.096 & 0.034 & 0.820 & 0.188 & -0.077 & 0.035 & 3.314 & 0.922 & 1.104 & 0.151 & 0.396 & 0.010 & 0.205 & 0.008 & 0.098 & 0.013 \\
\hline Hong Kong & 4.9 & 1.663 & 3.717 & 1.263 & 5.163 & 0.228 & 0.097 & 0.028 & 1.507 & 0.146 & -0.002 & 0.048 & 0.452 & 2.348 & 0.311 & 0.032 & 0.185 & 0.034 & 0.120 & 0.019 & 0.055 & 0.014 \\
\hline Hungary & 6.0 & 1.247 & 7.864 & 0.723 & 4.104 & 0.206 & -0.058 & 0.034 & 0.534 & 0.140 & -0.058 & 0.019 & 5.637 & 1.836 & 0.655 & 0.098 & 0.440 & 0.017 & 0.217 & 0.014 & 0.075 & 0.018 \\
\hline Iceland & 3.3 & 3.234 & & & 5.413 & 0.306 & -0.120 & 0.088 & 1.677 & 0.791 & -0.018 & 0.065 & 6.260 & 3.498 & 0.499 & 0.248 & 0.447 & 0.024 & 0.249 & 0.024 & 0.038 & 0.019 \\
\hline India & 10.5 & 0.850 & 6.922 & 1.086 & 3.892 & 0.268 & -0.007 & 0.015 & 0.400 & 0.080 & -0.035 & 0.014 & 6.363 & 3.071 & 0.780 & 0.052 & 0.191 & 0.014 & 0.098 & 0.012 & 0.070 & 0.022 \\
\hline Indonesia & 14.4 & 1.430 & & & 3.494 & 0.251 & 0.021 & 0.016 & 0.251 & 0.028 & -0.009 & 0.005 & 8.590 & 3.075 & 0.473 & 0.180 & 0.189 & 0.015 & 0.121 & 0.006 & 0.091 & 0.012 \\
\hline Ireland & 1.2 & 0.632 & 4.254 & 0.594 & 4.849 & 0.165 & -0.023 & 0.022 & 1.673 & 0.491 & -0.045 & 0.107 & 2.508 & 3.020 & 0.406 & 0.218 & 0.342 & 0.015 & 0.237 & 0.017 & 0.061 & 0.035 \\
\hline Israel & 5.7 & 0.483 & 6.623 & 2.556 & 4.904 & 0.229 & 0.017 & 0.021 & 0.908 & 0.055 & -0.046 & 0.021 & 2.163 & 1.926 & 0.871 & 0.093 & 0.440 & 0.028 & 0.265 & 0.017 & 0.086 & 0.016 \\
\hline Jamaica & 14.2 & 0.789 & & & 3.709 & 0.305 & -0.104 & 0.046 & 0.218 & 0.054 & -0.035 & 0.024 & 11.540 & 4.584 & 1.231 & 0.111 & 0.262 & 0.013 & 0.254 & 0.008 & 0.117 & 0.018 \\
\hline Japan & 1.6 & 0.699 & 1.382 & 0.227 & 5.026 & 0.154 & 0.034 & 0.007 & 1.819 & 0.066 & -0.044 & 0.020 & -0.263 & 0.759 & 1.841 & 0.191 & 0.298 & 0.012 & 0.094 & 0.009 & 0.047 & 0.005 \\
\hline Jordan & 12.3 & 0.483 & & & 3.812 & 0.281 & -0.051 & 0.095 & 0.795 & 0.081 & -0.038 & 0.024 & 4.299 & 4.274 & 0.814 & 0.151 & 0.311 & 0.036 & 0.200 & 0.034 & 0.134 & 0.017 \\
\hline Kazakhstan & 9.9 & 1.287 & 8.134 & 4.865 & 3.610 & 0.137 & -0.020 & 0.038 & 0.365 & 0.151 & 0.007 & 0.019 & 8.602 & 3.301 & 0.110 & 0.044 & 0.257 & 0.025 & 0.123 & 0.028 & 0.079 & 0.014 \\
\hline Latvia & 7.3 & 1.703 & & & 3.878 & 0.194 & -0.094 & 0.099 & 0.689 & 0.292 & -0.022 & 0.025 & 5.477 & 4.691 & 0.176 & 0.104 & 0.349 & 0.015 & 0.143 & 0.010 & 0.112 & 0.043 \\
\hline Lithuania & 7.8 & 1.814 & 6.250 & 3.040 & 3.989 & 0.312 & -0.064 & 0.060 & 0.429 & 0.214 & -0.027 & 0.030 & 3.052 & 3.441 & 0.221 & 0.068 & 0.329 & 0.015 & 0.163 & 0.017 & 0.110 & 0.048 \\
\hline
\end{tabular}


Table 3. Country - wise statistics of the main variables.

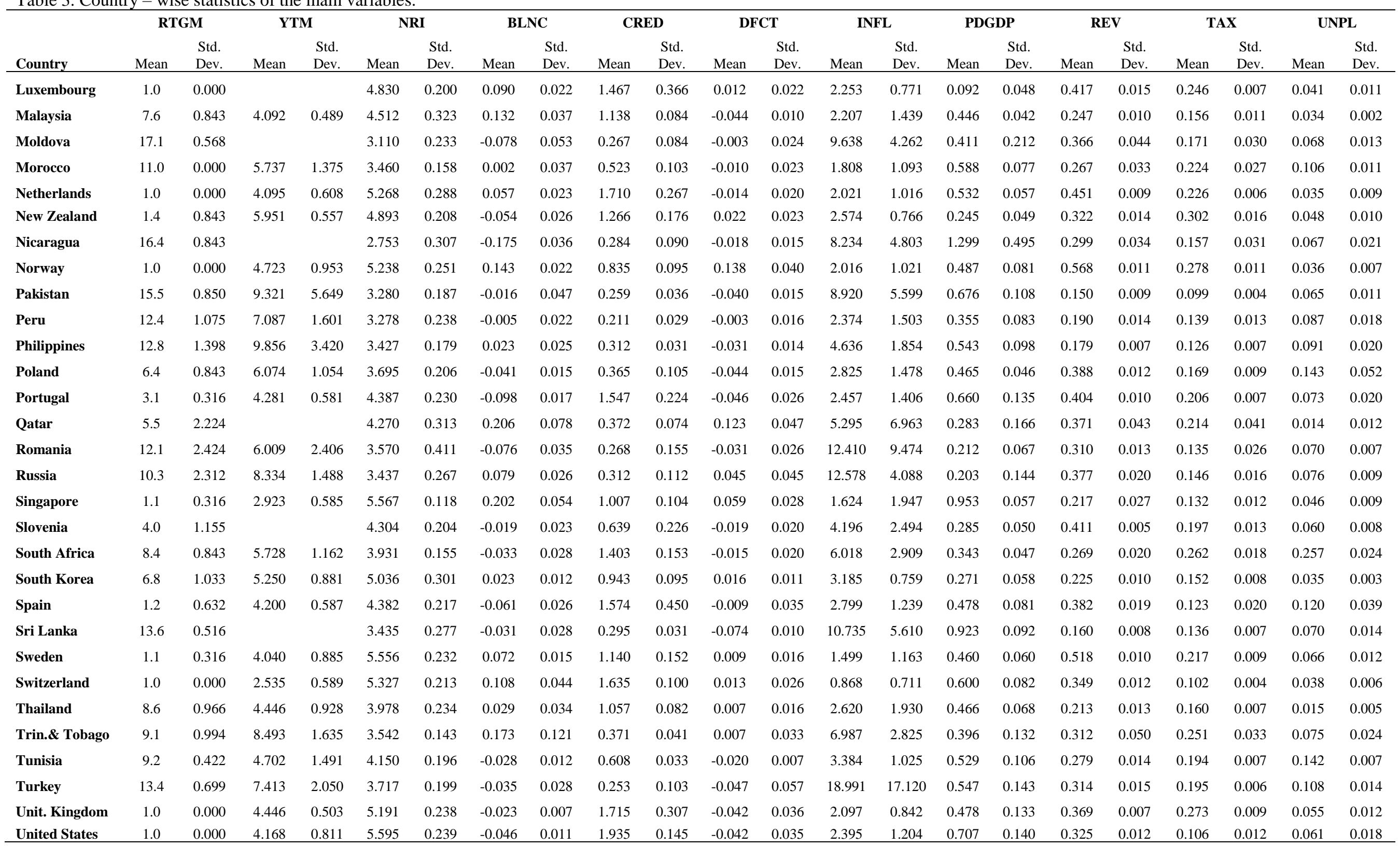


Table 4. Average values per year for OECD (upper line) and non-OECD (bottom line) countries.

\begin{tabular}{|c|c|c|c|c|c|c|c|c|c|c|c|c|c|}
\hline & 2001 & 2002 & 2003 & 2004 & 2005 & 2006 & 2007 & 2008 & 2009 & 2010 & $\begin{array}{l}\text { Average } \\
2001-10\end{array}$ & $\begin{array}{l}\text { \%change } \\
2001-10\end{array}$ & $\operatorname{Pr}(|\mathbf{T}|>|\mathbf{t}|)^{\mathbf{a}}$ \\
\hline RTGSP & 11.41 & 11.30 & 10.89 & 10.76 & 10.41 & 10.11 & 9.81 & 9.84 & 10.11 & 10.53 & 10.52 & 7.68 & 0.000 \\
\hline RTGM & 11.49 & 11.22 & 10.81 & 10.62 & 10.41 & 10.22 & 9.97 & 9.81 & 9.92 & 10.32 & 10.48 & 10.12 & 0.000 \\
\hline RTGF & 3.357 & 3.286 & 3.214 & 2.964 & 2.929 & 2.857 & 2.893 & 2.893 & 3.107 & 3.516 & 3.102 & -4.74 & 0.000 \\
\hline \multirow{2}{*}{ YTM } & 5.448 & 5.246 & 4.531 & 4.479 & 4.053 & 3.792 & 4.334 & 4.613 & 3.842 & 4.191 & 4.453 & -23.08 & \multirow{2}{*}{0.000} \\
\hline & 8.573 & 7.583 & 6.917 & 6.644 & 5.714 & 5.414 & 5.728 & 6.184 & 5.966 & 5.342 & 6.406 & -37.69 & \\
\hline \multirow{2}{*}{ NRI } & 5.005 & 4.907 & 4.554 & 4.600 & 4.839 & 4.982 & 4.982 & 5.039 & 4.861 & 4.807 & 4.858 & -3.97 & \multirow{2}{*}{0.000} \\
\hline & 3.596 & 3.649 & 3.537 & 3.662 & 3.778 & 3.905 & 4.005 & 4.043 & 3.927 & 3.929 & 3.803 & 9.26 & \\
\hline BLNC & 0.006 & 0.007 & 0.004 & 0.004 & -0.001 & -0.007 & -0.011 & -0.021 & -0.004 & 0.003 & -0.002 & -44.56 & 0.579 \\
\hline CRED & 0.438 & 0.435 & 0.450 & 0.465 & 0.497 & 0.526 & 0.573 & 0.584 & 0.607 & 0.572 & 0.515 & 30.54 & 0.000 \\
\hline \multirow{2}{*}{ CRPT } & 7.200 & 7.200 & 7.300 & 7.300 & 7.400 & 7.400 & 7.400 & 7.300 & 7.300 & 7.100 & 7.290 & -1.39 & \multirow{2}{*}{0.000} \\
\hline & 4.100 & 4.100 & 4.000 & 4.000 & 4.100 & 4.100 & 4.100 & 4.100 & 4.100 & 4.000 & 4.070 & -2.44 & \\
\hline \multirow{2}{*}{ DFCT } & -0.003 & -0.013 & -0.016 & -0.012 & -0.004 & 0.006 & 0.008 & -0.008 & -0.045 & -0.046 & -0.013 & -1355.41 & \multirow{2}{*}{0.781} \\
\hline & -0.018 & -0.018 & -0.016 & -0.012 & -0.006 & -0.005 & 0.001 & -0.010 & -0.035 & -0.029 & -0.015 & -57.58 & \\
\hline \multirow{2}{*}{ FDGDP } & 0.186 & 0.206 & 0.216 & 0.226 & 0.231 & 0.234 & 0.234 & 0.273 & 0.308 & 0.296 & 0.241 & 58.78 & \multirow{2}{*}{0.324} \\
\hline & 0.305 & 0.295 & 0.288 & 0.261 & 0.218 & 0.190 & 0.165 & 0.155 & 0.186 & 0.193 & 0.226 & -36.81 & \\
\hline \multirow{2}{*}{ FRDM } & 70.00 & 70.20 & 70.10 & 69.80 & 69.80 & 71.10 & 71.30 & 72.10 & 72.20 & 71.90 & 70.85 & 2.71 & \multirow{2}{*}{0.000} \\
\hline & 62.20 & 62.20 & 62.60 & 62.20 & 61.80 & 62.20 & 62.00 & 62.60 & 63.00 & 62.80 & 62.42 & 0.96 & \\
\hline PDCDP & 0.564 & 0.568 & 0.572 & 0.573 & 0.567 & 0.561 & 0.541 & 0.595 & 0.677 & 0.691 & 0.591 & 22.58 & 0000 \\
\hline FDUDF & 0.590 & 0.593 & 0.586 & 0.533 & 0.493 & 0.442 & 0.405 & 0.395 & 0.451 & 0.465 & 0.495 & -21.21 & 0.000 \\
\hline PFV & 0.415 & 0.410 & 0.412 & 0.410 & 0.416 & 0.419 & 0.419 & 0.415 & 0.408 & 0.408 & 0.413 & -1.68 & 0000 \\
\hline & 0.257 & 0.257 & 0.262 & 0.268 & 0.272 & 0.280 & 0.285 & 0.289 & 0.276 & 0.263 & 0.271 & 2.28 & 0.000 \\
\hline$T A Y$ & 0.205 & 0.201 & 0.200 & 0.200 & 0.206 & 0.208 & 0.209 & 0.205 & 0.194 & 0.195 & 0.202 & -5.07 & 0000 \\
\hline 1AX & 0.153 & 0.153 & 0.157 & 0.161 & 0.171 & 0.173 & 0.175 & 0.174 & 0.161 & 0.155 & 0.163 & 0.87 & 0.000 \\
\hline UNPL & 0.062 & 0.066 & 0.069 & 0.070 & 0.068 & 0.063 & 0.057 & 0.057 & 0.077 & 0.084 & 0.067 & 35.59 & 0.000 \\
\hline & 0.103 & 0.102 & 0.099 & 0.095 & 0.089 & 0.083 & 0.076 & 0.074 & 0.087 & 0.089 & 0.090 & -13.48 & \\
\hline
\end{tabular}

Notes: ${ }^{a}$ p-values of the Satterthwaite-Welch t-test that allows for unequal variances formatted in bold, depict statistically significant difference between averages of variables across all years for OECD (upper line) and non-OECD (bottom line) countries. 
Table 5.Correlation Analysis

\begin{tabular}{|c|c|c|c|c|c|}
\hline & RTGSP & RTGM & RTGF & YTM & NRI \\
\hline RTGM & $0.9831 *$ & & & & \\
\hline RTGF & $0.9928 *$ & $0.9858 *$ & & & \\
\hline YTM & $0.6309 *$ & $0.6331 *$ & $0.6436 *$ & & \\
\hline NRI & $-0.8672 *$ & $-0.8677 *$ & $-0.8738 *$ & $-0.5620 *$ & \\
\hline BLNC & $-0.3027 *$ & $-0.2572 *$ & $-0.2973 *$ & $-0.2383 *$ & $0.2848 *$ \\
\hline CRED & $-0.7507 *$ & $-0.7674 *$ & $-0.7657 *$ & $-0.5743 *$ & $0.7597 *$ \\
\hline CRPT & $-0.8814 *$ & $-0.8806 *$ & $-0.8790 *$ & $-0.5160 *$ & $0.8993 *$ \\
\hline DFCT & $-0.2652 *$ & $-0.2203 *$ & $-0.2475 *$ & $-0.1291 *$ & $0.2534 *$ \\
\hline FDGDP & $0.1921 *$ & $0.1781 *$ & $0.1874 *$ & -0.0121 & $-0.2499 *$ \\
\hline FRDM & $-0.6997 *$ & $-0.6961 *$ & $-0.6969 *$ & $-0.4311 *$ & $0.7344 *$ \\
\hline GNI & $-0.5594 *$ & $-0.5496 *$ & $-0.5784 *$ & $-0.3424 *$ & $0.5237 *$ \\
\hline HDI & $-0.8235 *$ & $-0.8293 *$ & $-0.8235 *$ & $-0.4749 *$ & $0.7450 *$ \\
\hline INFL & $0.5380 *$ & $0.5189 *$ & $0.5306 *$ & $0.5760 *$ & $-0.4317 *$ \\
\hline PDGDP & 0.0384 & 0.0048 & 0.0194 & $-0.2918 *$ & -0.0015 \\
\hline REV & $-0.6340 *$ & $-0.6372 *$ & $-0.6269 *$ & $-0.1988 *$ & $0.5389 *$ \\
\hline TAX & $-0.3423 *$ & $-0.3356 *$ & $-0.3289 *$ & -0.0394 & $0.3013 *$ \\
\hline UNPL & $0.3774 *$ & $0.3663 *$ & $0.3801 *$ & $0.3726 *$ & $-0.4139 *$ \\
\hline
\end{tabular}

Notes: A star denotes statistically significant values at the 5 percent level using a two-tailed test 
Table 6. Correlation analysis for OECD (upper line) and non-OECD (bottom line) countries

\begin{tabular}{|c|c|c|c|c|c|}
\hline & RTGSP & RTGM & RTGF & YTM & NRI \\
\hline \multirow{2}{*}{ RTGM } & $0.9569 *$ & & & & \\
\hline & $0.9708^{*}$ & & & & \\
\hline \multirow{2}{*}{ RTGF } & $0.9829^{*}$ & $0.9627 *$ & & & \\
\hline & $0.9866^{*}$ & $0.9729 *$ & & & \\
\hline \multirow{2}{*}{ YTM } & $0.4307 *$ & $0.4934^{*}$ & $0.5078^{*}$ & & \\
\hline & $0.6293^{*}$ & $0.5835^{*}$ & $0.6087^{*}$ & & \\
\hline \multirow{2}{*}{ NRI } & $-0.6755^{*}$ & $-0.6505^{*}$ & $-0.6784 *$ & $-0.3399 *$ & \\
\hline & $-0.8070 *$ & $-0.8193^{*}$ & $-0.8239 *$ & $-0.5866^{*}$ & \\
\hline \multirow{2}{*}{ BLNC } & $-0.3976^{*}$ & $-0.3102 *$ & $-0.3996^{*}$ & $-0.3506^{*}$ & $0.3985^{*}$ \\
\hline & $-0.4267 *$ & $-0.3905^{*}$ & $-0.4303 *$ & $-0.3818^{*}$ & $0.3475^{*}$ \\
\hline \multirow[t]{2}{*}{ CRED } & $-0.5456^{*}$ & $-0.6030^{*}$ & $-0.5817^{*}$ & $-0.4984 *$ & $0.5553 *$ \\
\hline & $-0.6372 *$ & $-0.6455^{*}$ & $-0.6501 *$ & $-0.6153^{*}$ & $0.6889 *$ \\
\hline \multirow{2}{*}{ CRPT } & $-0.7708^{*}$ & $-0.7674 *$ & $-0.7475^{*}$ & $-0.2967^{*}$ & $0.8147^{*}$ \\
\hline & $-0.7843 *$ & $-0.7846^{*}$ & $-0.7877 *$ & $-0.5052 *$ & $0.8289^{*}$ \\
\hline \multirow[t]{2}{*}{ DFCT } & $-0.3762 *$ & $-0.3227^{*}$ & $-0.3614^{*}$ & -0.0043 & 0.4293* \\
\hline & $-0.3791^{*}$ & $-0.3353^{*}$ & $-0.3604 *$ & $-0.3659 *$ & $0.2340 *$ \\
\hline \multirow{2}{*}{ FDGDP } & 0.0512 & 0.015 & 0.0272 & -0.004 & $-0.2526^{*}$ \\
\hline & $0.4603^{*}$ & $0.4623^{*}$ & $0.4785^{*}$ & $0.4541 *$ & $-0.4328^{*}$ \\
\hline \multirow[t]{2}{*}{ FRDM } & $-0.6084^{*}$ & $-0.6001 *$ & $-0.5916^{*}$ & $-0.1689 *$ & $0.6618^{*}$ \\
\hline & $-0.5903^{*}$ & $-0.5943^{*}$ & $-0.5967 *$ & $-0.4769 *$ & $0.6373 *$ \\
\hline \multirow{2}{*}{ GNI } & $-0.2427^{*}$ & $-0.1866^{*}$ & $-0.2627^{*}$ & $-0.4590 *$ & $0.1540 *$ \\
\hline & $-0.2783^{*}$ & $-0.2535^{*}$ & $-0.3047 *$ & 0.0270 & $0.3147^{*}$ \\
\hline \multirow[t]{2}{*}{ HDI } & $-0.7449 *$ & $-0.7600 *$ & $-0.7321^{*}$ & $-0.3450^{*}$ & $0.5711^{*}$ \\
\hline & $-0.6380^{*}$ & $-0.6285^{*}$ & $-0.6333^{*}$ & $-0.2884 *$ & $0.5513^{*}$ \\
\hline \multirow{2}{*}{ INFL } & $0.5833 *$ & 0.5833* & $0.5805^{*}$ & $0.6421^{*}$ & $-0.3019 *$ \\
\hline & $0.4257^{*}$ & $0.3983^{*}$ & $0.4167^{*}$ & $0.4616^{*}$ & $-0.3332^{*}$ \\
\hline \multirow[t]{2}{*}{ PDGDP } & 0.1006 & 0.0256 & 0.0712 & $-0.4409^{*}$ & $-0.1307^{*}$ \\
\hline & $0.2804 *$ & $0.2680 *$ & $0.2684 *$ & -0.0971 & $-0.1211^{*}$ \\
\hline \multirow[t]{2}{*}{ REV } & $-0.3548^{*}$ & $-0.3635^{*}$ & $-0.3320 *$ & 0.0131 & $0.2327^{*}$ \\
\hline & $-0.3091^{*}$ & $-0.2821^{*}$ & $-0.2809^{*}$ & 0.1232 & $0.1915^{*}$ \\
\hline \multirow[t]{2}{*}{ TAX } & $-0.1262^{*}$ & $-0.1189^{*}$ & -0.0893 & $0.3347^{*}$ & 0.1009 \\
\hline & $-0.1941^{*}$ & $-0.1660^{*}$ & $-0.1772 *$ & -0.1344 & $0.1408 *$ \\
\hline \multirow[t]{2}{*}{ UNPL } & $0.3877 *$ & $0.3935^{*}$ & $0.4013 *$ & $0.1580 *$ & $-0.5607 *$ \\
\hline & $0.2405^{*}$ & $0.2184 *$ & $0.2414 *$ & $0.5556 *$ & $-0.2259 *$ \\
\hline
\end{tabular}


Table 7. Baseline Regression for all countries

\begin{tabular}{|c|c|c|c|c|c|c|c|}
\hline & \multirow{2}{*}{$\begin{array}{c}\text { RTGSP } \\
\text { Random } \\
\text { Effects }\end{array}$} & \multirow{2}{*}{$\begin{array}{c}\text { RTGM } \\
\text { Random } \\
\text { Effects } \\
\end{array}$} & \multirow{2}{*}{$\begin{array}{c}\text { RTGF } \\
\text { Random } \\
\text { Effects }\end{array}$} & \multicolumn{2}{|c|}{ YTM } & \multicolumn{2}{|c|}{ exCoD } \\
\hline & & & & Random Effects & Fixed Effects & Random Effects & Fixed Effects \\
\hline NRI_AVG & $-0.9493 * *$ & $-1.6672 * *$ & $-0.7406^{* *}$ & $-1.0705^{*}(0.5241)$ & & $-1.5178 *(0.7227)$ & \\
\hline NRI_DIFF/NRI & -0.0160 & 0.2149 & 0.0590 & $0.2961(0.3048)$ & $0.3007(0.2959)$ & $0.6291(0.4119)$ & $0.6381(0.4131)$ \\
\hline BLNC_AVG & $-12.9623 * *$ & $-3.3343^{*}$ & $-14.5711^{* *}$ & & & & \\
\hline BLNC_DIFF & 0.3008 & 1.0677 & 1.3501 & & & & \\
\hline CRED_AVG & $-2.0741 * *$ & $-2.0491 * *$ & $-1.0924 * *$ & $-1.8406^{* *}(0.3964)$ & & $-1.8618 * *(0.7009)$ & \\
\hline CRED_DIFF/CRED & 0.0234 & $-1.3390 * *$ & 0.1967 & $0.3398(0.4520)$ & $0.3345(0.4388)$ & $0.4049(0.6147)$ & $0.4175(0.6168)$ \\
\hline CRPT_AVG & $-0.9312 * *$ & & $-0.8924 * *$ & & & & \\
\hline CRPT_DIFF & $-0.4555^{* *}$ & & $-0.3482 *$ & & & & \\
\hline DFCT_AVG & & $-19.5601 * *$ & $-17.7894 * *$ & $-16.2059 * *(3.9191)$ & & $-9.4161(7.0489)$ & \\
\hline DFCT_DIFF/DFCT & & -3.7224 & $-8.5438 * *$ & $-10.2233^{* *}(3.0797)$ & $-10.3019^{* *}(2.9890)$ & $-4.4077(3.6796)$ & $-4.2857(3.6988)$ \\
\hline FDGDP_AVG & $-2.3531 * *$ & $0.8733^{*}$ & $3.8813 * *$ & & & & \\
\hline FDGDP_DIFF & 0.4605 & 0.8507 & $1.3456^{*}$ & & & & \\
\hline FRDM_AVG & -0.0060 & $-0.0350 *$ & -0.0136 & $0.0932 * *(0.0322)$ & & $0.0680(0.0447)$ & \\
\hline FRDM_DIFF/FRDM & $-0.0672 * *$ & $-0.0769 * *$ & $-0.0864^{* *}$ & $0.1091^{* * *}(0.0333)$ & $0.1086^{* *}(0.0323)$ & $0.1693 * *(0.0365)$ & $0.1710 * *(0.0366)$ \\
\hline GNI_AVG & $-0.5035^{* *}$ & 0.0631 & -0.0113 & $-0.0016(0.1484)$ & & $0.3937(0.2350)$ & \\
\hline GNI_DIFF/GNI & $-0.8471 * *$ & $-1.5426^{* *}$ & $-1.6311^{* *}$ & $-2.1414 * *(0.2580)$ & $-2.1448 * *(0.2504)$ & $-1.7193 * *(0.3278)$ & $-1.7456^{* *}(0.3290)$ \\
\hline HDI_AVG & & $-6.1846^{* *}$ & & & & & \\
\hline HDI_DIFF & & $-7.9324 * *$ & & & & & \\
\hline INFL_AVG & $0.2821 * *$ & $0.2189 * *$ & $0.3686^{* *}$ & $0.5255 * *(0.0843)$ & & $0.0916(0.0686)$ & \\
\hline INFL_DIFF/INFL & $0.0476^{* *}$ & 0.0182 & $0.0255^{*}$ & $0.2623 * *(0.0377)$ & $0.2620 * *(0.0366)$ & $0.1441 * *(0.0200)$ & $0.1444 * *(0.0200)$ \\
\hline PDGDP_AVG & $4.5108 * *$ & & & $-1.3147 * *(0.4055)$ & & $-1.9539 *(0.8188)$ & \\
\hline PDGDP_DIFF/PDGDP & $2.2909 * *$ & & & $-0.4818(0.7956)$ & $-0.4782(0.7724)$ & $0.7208(1.0611)$ & $0.6889(1.0646)$ \\
\hline REV_AVG & $-14.2792 * *$ & $-11.5038 * *$ & $-13.2808 * *$ & $5.9895 *(2.8614)$ & & $4.1422(4.8096)$ & \\
\hline REV_DIFF/REV & -1.9599 & $5.8054^{*}$ & 4.0767 & $8.9694(5.6733)$ & $9.1622(5.5043)$ & $9.4170(6.9471)$ & $11.4848(7.1120)$ \\
\hline TAX_AVG & $5.5140 * *$ & $12.1787 * *$ & $11.5739 * *$ & $2.2177(3.0742)$ & & $2.1716(5.5996)$ & \\
\hline TAX_DIFF/TAX & -1.6330 & 0.3424 & -0.3119 & $-6.7262(7.1180)$ & $-6.5601(6.9087)$ & $-7.5004(7.7395)$ & $-10.6957(8.2582)$ \\
\hline UNPL_AVG & 2.1679 & $-5.5566^{* *}$ & $-8.3161 * *$ & $10.6447(5.8985)$ & & $-0.6510(5.5072)$ & \\
\hline UNPL_DIFF/UNPL & $19.6414^{* *}$ & $11.8290^{* *}$ & $14.9329 * *$ & $1.8043(3.7385)$ & $1.8509(3.6295)$ & $-1.4145(5.0297)$ & $-1.7243(5.0500)$ \\
\hline DFLT75 & & $0.7604 * *$ & & & & & \\
\hline DFLT95 & & -0.0266 & & & & & \\
\hline EURO & $-1.0514 * *$ & $-2.2684 * *$ & $-3.7601 * *$ & $-2.0932 * *(0.3580)$ & & $-0.9302(0.6788)$ & \\
\hline OECD & $-1.8628^{* *}$ & $-2.3598 * *$ & $-2.4738^{* *}$ & $-0.3571(0.4024)$ & & $-0.8044(0.6905)$ & \\
\hline LGLGRM & -0.3240 & 0.6872 & -0.1900 & & & & \\
\hline LGLSKN & $2.0081^{* *}$ & $-1.2656^{*}$ & & $-0.7012(0.5837)$ & & $0.1034(1.1334)$ & \\
\hline LGLSOC & & & & $-3.7988 * *(0.5445)$ & & $-1.5210(0.8040)$ & \\
\hline LGLUK & $-1.1076^{* *}$ & $-0.9494 * *$ & $-1.5279 * *$ & $-0.9725^{* *}(0.3600)$ & & $-0.2561(0.5729)$ & \\
\hline _CONS & & & & $3.1581(4.1059)$ & $49.9523 * *(6.5306)$ & $-1.2251(6.9911)$ & $33.8872 * *(8.1979)$ \\
\hline LogLik & $-675.045^{* *}$ & $-695.93 * *$ & $-683.23 * *$ & & & & \\
\hline R-squared & & & & 0.7394 & 0.0635 & 0.5109 & 0.0023 \\
\hline Rho $^{\mathrm{a}}$ & 0.7954 & 0.7801 & 0.7723 & 0.1663 & 0.8939 & 0.3321 & 0.8075 \\
\hline N. Obs & 650 & 650 & 650 & 360 & 360 & 496 & 496 \\
\hline
\end{tabular}

Notes: In order for our maximum-likelihood estimation to converge, we merged S\&P ratings between 17-20 to 17 (4 changes made), Moody's ratings between 17-18 to 17 (2 changes made) and Fitch ratings between 17-21 to 17 (1 change made). The coefficient with the variable followed by_AVG denotes the long-run coefficient while the coefficient with the variable followed by_DIFF denotes the short-run coefficient. Errors are standard. (*), (**) denotes statistical significance at 5 percent, 1 percent. Errors in parentheses provided for comparison reasons between fixed and random effects. According to the results, both models produce similar within panel effects and standard errors. Any discrepancies are mainly due to the inclusion of time invariant regressors. Therefore, it can be assumed that the correlation between the country specific error and the regressors is removed. Variables in italics represent the non - transformed initial variables used in fixed effects models.

${ }^{\mathrm{a}}$ Fraction of variance that occurs at country level or the intraclass correlation. 
Table 8. Regressions for OECD countries

\begin{tabular}{|c|c|c|c|c|c|c|c|}
\hline & \multirow{2}{*}{$\begin{array}{c}\text { RTGSP } \\
\text { Random Effects } \\
\end{array}$} & \multirow{2}{*}{$\begin{array}{c}\text { RTGM } \\
\text { Random Effects } \\
\end{array}$} & \multirow{2}{*}{$\begin{array}{c}\text { RTGF } \\
\text { Random Effects } \\
\end{array}$} & \multicolumn{2}{|c|}{ YTM } & \multicolumn{2}{|c|}{ exCoD } \\
\hline & & & & Random Effects & Fixed Effects & Random Effects & Fixed Effects \\
\hline NRI_AVG & 1.9970 & -1.2055 & & & & & \\
\hline NRI_DIFF/ NRI & -0.3246 & $1.2638 *$ & & & & & \\
\hline BLNC_AVG & $-45.1795^{* *}$ & -7.6187 & $-34.5925^{* *}$ & & & & \\
\hline BLNC_DIFF/BLNC & 6.5342 & $25.1513 * *$ & 8.0091 & & & & \\
\hline CRED_AVG & $-7.9416^{* *}$ & $-3.4561 * *$ & $-9.4273 * *$ & $-0.4535(0.2601)$ & & $-0.1874(0.4343)$ & \\
\hline CRED_DIFF/CRED & 0.1472 & $-2.6696^{* *}$ & $2.6770 * *$ & $0.6297 *(0.2443)$ & $0.6294 *(0.2442)$ & $0.5767 *(0.2532)$ & $0.5765 *(0.2535)$ \\
\hline CRPT_AVG & -0.5485 & -0.8984 & $-3.8723 * *$ & & & & \\
\hline CRPT_DIFF/CRPT & $-1.6664 * *$ & $-1.0718 * *$ & $-1.4402 * *$ & & & & \\
\hline DFCT_AVG & & -9.7951 & -19.0273 & & & & \\
\hline DFCT_DIFF/DFCT & & $-35.9636^{* *}$ & -7.5810 & & & & \\
\hline FDGDP_DIFF/FDGDP & $4.1157 *$ & & 2.8425 & $0.7792(0.7635)$ & $0.7807(0.7631)$ & $0.3372(0.7841)$ & $0.3383(0.7848)$ \\
\hline FRDM_AVG & $-0.3188^{* *}$ & $-0.2434^{*}$ & 0.1035 & & & & \\
\hline FRDM_DIFF/FRDM & $-0.1671^{*}$ & -0.0114 & -0.0666 & & & & \\
\hline GNI_AVG & & & $-3.5061 * *$ & $0.0857(0.0831)$ & & $0.1029(0.1402)$ & \\
\hline GNI_DIFF/GNI & & & $-4.3677 * *$ & $-1.7971^{* *}(0.1882)$ & $-1.8002 * *(0.1884)$ & $-1.6841 * *(0.1926)$ & $-1.6865 * *(0.1930)$ \\
\hline HDI_AVG & & & -30.2879 & & & & \\
\hline HDI_DIFF/HDI & & & $13.5892 *$ & & & & \\
\hline INFL_AVG & $1.8734^{* *}$ & $0.6579 * *$ & $1.5154 * *$ & $0.7522 * *(0.1066)$ & & $0.1994 * *(0.0453)$ & \\
\hline INFL_DIFF/INFL & $0.3332 * *$ & $0.5171 * *$ & $0.2264 *$ & $0.1752 * *(0.0349)$ & $0.1750 * *(0.0349)$ & $0.0759^{* *}(0.0120)$ & $0.0758 * *(0.0121)$ \\
\hline PDGDP_AVG & $10.3598 * *$ & & $10.8257^{* *}$ & $-0.5811(0.3362)$ & & $-1.3941 * *(0.5040)$ & \\
\hline PDGDP_DIFF/PDGDP & $9.0164 * *$ & & $14.9529 * *$ & $0.5367(0.5426)$ & $0.5462(0.5431)$ & $0.2394(0.5578)$ & $0.2470(0.5588)$ \\
\hline REV_DIFF/REV & 9.6996 & 24.7771 & 15.3047 & & & & \\
\hline TAX_AVG & $22.8588 * *$ & 2.5516 & -4.2216 & $5.4154 * *(1.8429)$ & & $5.9048(3.1526)$ & \\
\hline TAX_DIFF/TAX & 1.0132 & 5.7536 & 0.2887 & $-2.6294(3.4093)$ & $-2.4872(3.4360)$ & $-2.6414(3.5067)$ & $-2.5258(3.5262)$ \\
\hline UNPL_AVG & 34.1301 & -6.8458 & 24.4086 & $6.3743(4.1697)$ & & $5.5550(7.0680)$ & \\
\hline UNPL_DIFF/UNPL & $23.2029 * *$ & 11.4162 & -7.0706 & $-4.4668(2.5749)$ & $-4.4366(2.5754)$ & $-6.0340 *(2.5796)$ & $-6.0075 *(2.5832)$ \\
\hline DFLT75 & 0.9245 & -0.0520 & 2.3060 & & & & \\
\hline EURO & -1.2525 & $-4.0779 * *$ & $-7.5500 * *$ & $-0.4282(0.3056)$ & & $-0.7703(0.5123)$ & \\
\hline LGLGRM & & & & $0.4599(0.2847)$ & & $0.5611(0.4865)$ & \\
\hline LGLSOC & & $-3.1069 *$ & $-16.4932 * *$ & $0.3480(0.4161)$ & & $1.5694 * *(0.5880)$ & \\
\hline LGLUK & $-5.1251 * *$ & -0.2477 & -1.6057 & $0.3941(0.2208)$ & & $0.7507 *(0.3541)$ & \\
\hline$=$ CONS & & & & $-0.4144(2.4612)$ & $52.2135 * *(5.0817)$ & $-0.3058(4.1762)$ & $\begin{array}{c}49.9208 * * \\
(5.2293) \\
\end{array}$ \\
\hline LogLik & $-129.879 * *$ & $-142.723^{* *}$ & $-105.669 * *$ & & & & \\
\hline R-squared & & & & 0.8162 & 0.1817 & 0.7815 & 0.1825 \\
\hline $\mathrm{Rho}^{\mathrm{a}}$ & 0.9697 & 0.6785 & 0.2349 & 0.23179 & 0.9247 & 0.4985 & 0.9123 \\
\hline N. Obs & 283 & 283 & 283 & 251 & 251 & 261 & 261 \\
\hline 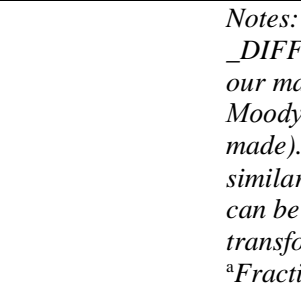 & $\begin{array}{l}\text { he coefficient with } \\
\text { lenotes the short-ru } \\
\text { imum-likelihood est } \\
\text { ratings between ( } 8 \text { - } \\
\text { rrors in parentheses } \\
\text { vithin panel effects } \\
\text { ssumed that the cor } \\
\text { ned initial variable. } \\
n \text { of variance that or }\end{array}$ & $\begin{array}{l}\text { e variable followed } \\
\text { coefficient. Errors } \\
\text { mation to converge, } \\
10 \text { to } 8,12-13 \text { to } 13) \\
\text { provided for compa } \\
\text { nd standard errors. } \\
\text { elation between the } \\
\text { used in fixed effects } \\
\text { curs at country leve }\end{array}$ & $\begin{array}{l}\text { y_AVG denotes the } \\
\text { re standard. (*), ( } \\
\text { ve merged } S \& P \text { rat } \\
4 \text { changes made) an } \\
\text { on reasons betweer } \\
\text { ny discrepancies at } \\
\text { untry specific erro } \\
\text { nodels. } \\
\text { or the intraclass co }\end{array}$ & $\begin{array}{l}\text { ong-run coefficient } w \\
\text { ) denotes statistical st } \\
\text { gs between }(9-10 \text { to } \\
\text { Fitch ratings between } \\
\text { ixed and random effec } \\
\text { mainly due to the inc } \\
\text { and the regressors is } \\
\text { elation }\end{array}$ & $\begin{array}{l}\text { le the coefficient with } \\
\text { nificance at } 5 \text { percen } \\
12-13 \text { to } 13,14-16 \\
14-16 \text { to } 14,11-13 \text { to } \\
\text { According to the rest } \\
\text { sion of time invariant } \\
\text { moved. Variables in } i\end{array}$ & $\begin{array}{l}\text { he variable followed } \\
1 \text { percent. In order } \\
\text { 16) (4 changes made } \\
1,9-10 \text { to 9) (8 chang } \\
\text { ts, both models produ } \\
\text { egressors. Therefore, } \\
\text { alics represent the nor }\end{array}$ & \\
\hline
\end{tabular}


Table 9. Regressions for non - OECD countries

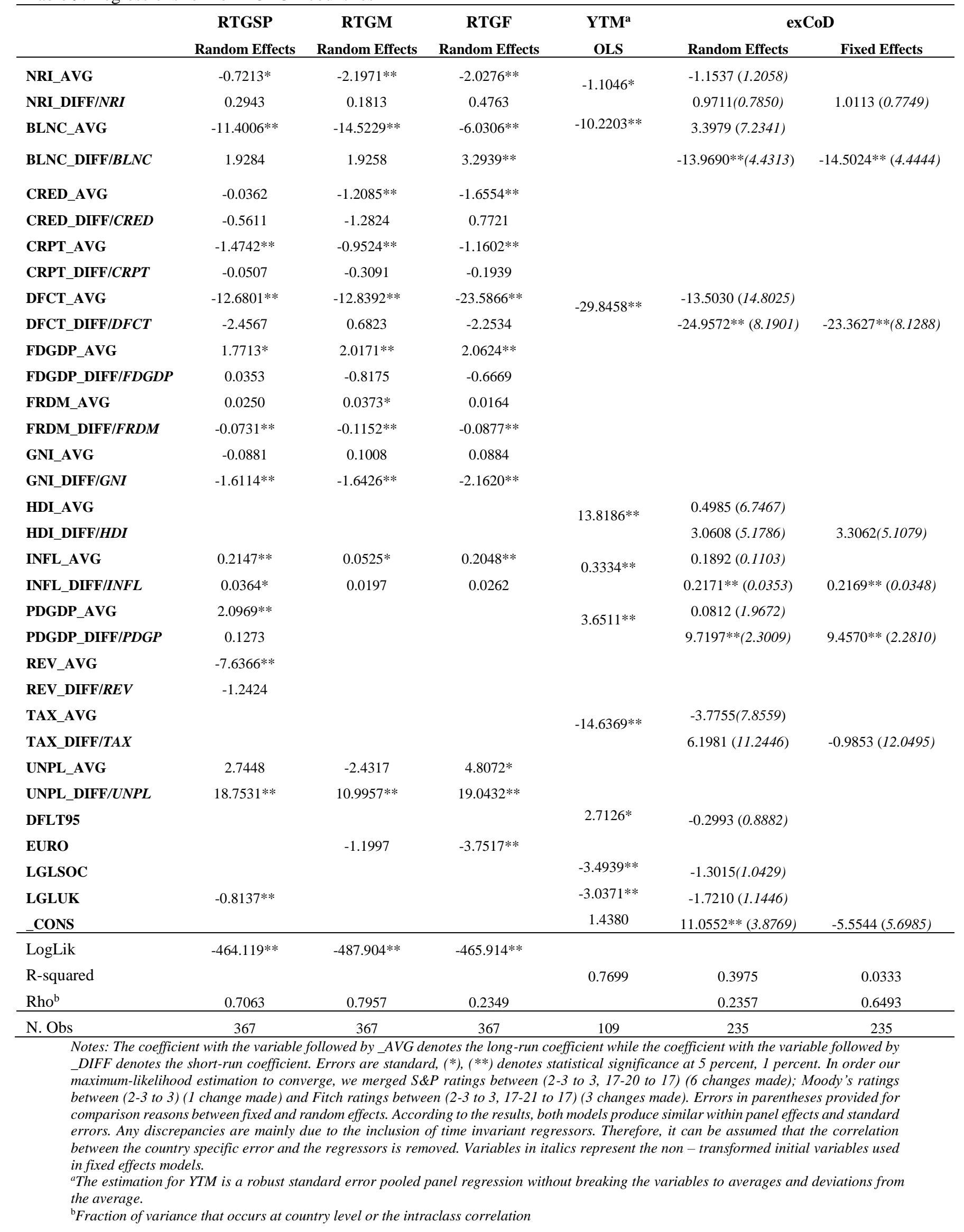


Table10. Regressions 2001-2006 \& 2007-2010. Robustness Check.

\begin{tabular}{|c|c|c|c|c|c|c|c|c|c|c|}
\hline & \multicolumn{2}{|c|}{$\begin{array}{c}\text { RTGSP } \\
\text { (Random Effects) }\end{array}$} & \multicolumn{2}{|c|}{$\begin{array}{c}\text { RTGM } \\
\text { (Random Effects) }\end{array}$} & \multicolumn{2}{|c|}{$\begin{array}{c}\text { RTGF } \\
\text { (Random Effects) }\end{array}$} & \multicolumn{2}{|c|}{$\begin{array}{c}\text { YTM } \\
\text { (Random Effects) }\end{array}$} & \multicolumn{2}{|c|}{$\begin{array}{c}\text { exCoD } \\
\text { (Random Effects) }\end{array}$} \\
\hline & $2001-2006$ & $2007-2010$ & $2001-2006$ & $2007-2010$ & $2001-2006$ & $2007-2010$ & 2001-2006 & $2007-2010$ & 2001-2006 & $2007-2010$ \\
\hline NRI_AVG & $-1.1246^{*}$ & -1.4189 & $-2.2933 * *$ & $-3.5412 * *$ & $-1.1801 * *$ & $-2.4594 * *$ & -1.2130 & -0.3235 & -1.5424 & -0.4924 \\
\hline NRI_DIFF & -0.4644 & 1.7753 & -0.0797 & -1.3905 & -0.2657 & -0.8975 & 0.2480 & 0.8009 & 0.4075 & -0.4786 \\
\hline BLNC_AVG & $-20.0806^{* *}$ & $-35.7416^{* *}$ & $-7.0230 * *$ & $-8.3607 *$ & -2.2536 & $-21.9490 * *$ & & & & \\
\hline BLNC_DIFF & 0.9820 & $10.7241 * *$ & 1.0566 & 4.0135 & 1.8724 & $13.5271^{* *}$ & & & & \\
\hline CRED_AVG & $-2.0009 * *$ & 0.2328 & $-1.3376^{* *}$ & -0.9794 & -0.5884 & 0.1156 & $-1.8433 *$ & $-1.2489^{*}$ & $-1.8958^{*}$ & -1.0921 \\
\hline CRED_DIFF & 0.2558 & $-6.1946 * *$ & $-2.0847 *$ & $-5.9749 * *$ & 0.7913 & $-4.6014 * *$ & -0.3233 & 0.3162 & 1.2091 & 0.7109 \\
\hline CRPT_AVG & $-2.1804 * *$ & $-4.2568 * *$ & & & $-2.0490 * *$ & $-2.5713^{* *}$ & & & & \\
\hline CRPT_DIFF & -0.4298 & $-1.5708 * *$ & & & $-0.8126^{* *}$ & $-1.2875^{* *}$ & & & & \\
\hline DFCT_AVG & & & $-17.2623^{* *}$ & $-51.9223^{* *}$ & $-30.8700^{* *}$ & $-65.1731 * *$ & $-21.8161 * *$ & $-11.6111^{*}$ & $-15.2995^{*}$ & -5.1023 \\
\hline DFCT_DIFF & & & 7.5653 & $9.6595 *$ & 4.2288 & $-12.3667 * *$ & $-21.4751 * *$ & -4.9363 & -4.6617 & 0.5892 \\
\hline FDGDP_AVG & $-1.8166^{*}$ & $4.1952 *$ & $2.2424 * *$ & $8.6832 * *$ & $2.5374 * *$ & $13.4406^{* *}$ & & & & \\
\hline FDGDP_DIFF & 1.5802 & -3.8567 & -1.5892 & $4.8870^{*}$ & 0.2329 & 0.7233 & & & & \\
\hline FRDM_AVG & 0.0038 & $-0.0961 *$ & -0.0099 & $-0.2288 * *$ & 0.0086 & $-0.1387^{* *}$ & 0.1145 & 0.0386 & 0.0931 & 0.0146 \\
\hline FRDM_DIFF & $-0.1611^{* *}$ & $-0.3176^{* *}$ & $-0.1687 * *$ & -0.1134 & $-0.2308 * *$ & $-0.1705^{* *}$ & $0.1368 * *$ & -0.0590 & $0.1213^{* *}$ & -0.0130 \\
\hline GNI_AVG & $-0.2080^{*}$ & $-2.7144 * *$ & $0.5135^{* *}$ & $-0.8148 * *$ & $-0.2014 *$ & $-1.8940^{* *}$ & 0.0186 & -0.1194 & $0.5188^{*}$ & 0.0590 \\
\hline GNI_DIFF & $-3.2423 * *$ & -0.5133 & $-2.6137 * *$ & $-4.8249 * *$ & $-4.0011 * *$ & $-2.3393^{*}$ & $-2.4919 * *$ & 1.9706 & $-3.0313^{* *}$ & -0.4553 \\
\hline HDI_AVG & & & $-13.6316^{* *}$ & $-16.7984 * *$ & & & & & & \\
\hline HDI_DIFF & & & $-16.7481 * *$ & $-7.0468 *$ & & & & & & \\
\hline INFL_AVG & $0.3792 * *$ & $1.0128 * *$ & $0.3229 * *$ & $0.3995 * *$ & $0.4823 * *$ & $0.5706^{* *}$ & $0.6184^{* *}$ & $0.4526^{* *}$ & 0.0637 & $0.4067 * *$ \\
\hline INFL_DIFF & $0.0534 * *$ & 0.0088 & 0.0184 & 0.0040 & 0.0172 & 0.0273 & $0.2382 * *$ & $0.1659 * *$ & $0.0655^{* *}$ & $0.4900^{* *}$ \\
\hline PDGDP_AVG & $4.1680 * *$ & $10.0445^{* *}$ & & & & & -1.3363 & -0.9074 & $-2.2244^{*}$ & $-2.0016^{*}$ \\
\hline PDGDP_DIFF & -0.3610 & $17.1438 * *$ & & & & & -1.3862 & 1.0592 & 1.1020 & 3.4871 \\
\hline REV_AVG & $-21.0933^{* *}$ & $-42.2974 * *$ & $-10.6641^{* *}$ & $-16.2706^{* *}$ & $-15.1178^{* *}$ & $-29.2464 * *$ & 5.9783 & 4.5683 & 6.6803 & -3.1940 \\
\hline REV_DIFF & -0.6190 & -0.8925 & 5.8951 & -2.4201 & 6.4834 & -4.1452 & $18.5957^{*}$ & 8.8984 & 8.0605 & -14.7761 \\
\hline TAX_AVG & $17.8363^{* *}$ & $21.5214^{* *}$ & $10.8177 * *$ & 4.4088 & $26.8880^{* *}$ & $21.8595 * *$ & 1.3922 & 2.9643 & 3.4743 & 2.5561 \\
\hline TAX_DIFF & 2.8250 & 12.8688 & 0.9814 & 2.3078 & -6.6258 & 12.1185 & -10.4151 & 12.5373 & -9.0952 & 15.8758 \\
\hline UNPL_AVG & 2.5203 & 4.7304 & -4.6412 & -5.1004 & $-8.6640 * *$ & $-10.2051^{*}$ & 10.5000 & 12.2188 & 0.4199 & -2.5484 \\
\hline UNPL_DIFF & $14.2640 * *$ & $47.0723 * *$ & 4.3369 & $22.9106^{* *}$ & 1.7039 & $52.1652 * *$ & $17.8124^{* *}$ & 2.0151 & 8.0306 & 3.3600 \\
\hline DFLT75 & & & $1.0827 * *$ & $1.0928 *$ & & & & & & \\
\hline DFLT95 & & & $-1.3866^{* *}$ & -0.0721 & & & & & & \\
\hline EURO & $-4.2226 * *$ & $-9.1480 * *$ & $-4.2516^{* *}$ & $-5.9915 * *$ & $-7.1404 * *$ & $-11.5476^{* *}$ & $-2.1562 * *$ & $-1.4238 * *$ & -1.4322 & -0.0304 \\
\hline OECD & $-3.2810 * *$ & -0.6369 & $-4.8434 * *$ & $-3.2704 * *$ & $-4.0773 * *$ & $-2.9337 * *$ & -0.3486 & 0.2308 & -1.0727 & 0.1989 \\
\hline LGLGRM & 0.1056 & $-4.2086^{*}$ & 0.3076 & -0.5696 & -0.2589 & -0.7651 & & & & \\
\hline LGLSKN & $5.9371 * *$ & $5.4184 * *$ & $-2.0400^{*}$ & -1.0919 & & & -0.1322 & -1.0310 & -0.2389 & 0.0379 \\
\hline LGLSOC & & & & & & & $-4.7862 * *$ & $-2.1552 * *$ & $-2.6459 * *$ & -0.2143 \\
\hline LGLUK & -0.4447 & $-5.0808 * *$ & $-2.4269 * *$ & $-2.5724 * *$ & $-3.4062 * *$ & $-3.9920^{* *}$ & -0.9040 & -0.4852 & -0.7207 & -0.9617 \\
\hline _CONS & & & & & & & 1.6546 & 4.2392 & -6.7170 & 6.5758 \\
\hline LogLik & $-357.335 * *$ & $-162.862 * *$ & $-391.717 * *$ & $-207.886^{* *}$ & $-347.323^{* *}$ & $-181.335^{* *}$ & & & & \\
\hline R-squared & & & & & & & 0.7954 & 0.7591 & 0.6314 & 0.5762 \\
\hline $\mathrm{Rho}^{\mathrm{a}}$ & 0.8434 & 0.9619 & 0.8993 & 0.9425 & 0.8917 & 0.9514 & 0.5774 & 0.2486 & 0.5218 & 0.2586 \\
\hline N.obs & 390 & 260 & 390 & 260 & 390 & 260 & 216 & 144 & 299 & 197 \\
\hline Chow Test $^{\mathrm{b}}$ & 3.8 & & & & 4.6 & & & & 4.0 & \\
\hline
\end{tabular}

Notes: The coefficient with the variable followed by_AVG denotes the long-run coefficient while the coefficient with the variable followed by_DIFF denotes the short-run coefficient. Errors are standard. (*), (**) denotes statistical significance at 5 percent, 1 percent.

${ }^{\mathrm{a}}$ Fraction of variance that occurs at country level or the intraclass correlation

${ }^{\mathrm{b}}$ The formula for the Chow test is: $\frac{\frac{e s s_{C}-\left(e s s_{1}+e s s_{2}\right)}{k}}{\frac{e s s_{1}+e s s_{2}}{N_{1}+N_{2}-2 * k}}$ and the resulting test statistic is distributed $F\left(k, N_{-} \_1+N_{-} 2-2 * k\right)$.Our null hypothesis is that coefficients are constant across the two periods. 
Table 11. Regressions with alternative proxies of e-readiness. Total sample

\begin{tabular}{|c|c|c|c|c|c|c|c|c|c|c|}
\hline & $\begin{array}{r}\mathbf{R T} \\
\text { (Randor }\end{array}$ & $\begin{array}{l}\text { ESP } \\
\text { Effects) }\end{array}$ & $\begin{array}{r}\text { RT } \\
\text { (Randol }\end{array}$ & $\begin{array}{l}\text { SM } \\
\text { Effects) }\end{array}$ & $\begin{array}{r}\mathbf{R}^{\prime} \\
\text { (Randol }\end{array}$ & $\begin{array}{l}\text { GF } \\
\text { Effects) }\end{array}$ & $\begin{array}{r}\mathbf{Y} \\
\text { (RandoI } \\
\end{array}$ & $\begin{array}{l}\text { M } \\
\text { Effects) }\end{array}$ & $\begin{array}{r}\text { ex } \\
\text { (Rando }\end{array}$ & $\begin{array}{l}\text { oD } \\
\text { Effects) }\end{array}$ \\
\hline $\begin{array}{r}\text { INDEX_AVG } \\
\text { EIU }\end{array}$ & 0.0756 & & -0.3551 & & -0.3932 & & -0.7095 & & $-1.0798^{*}$ & \\
\hline $\begin{array}{r}\text { INDEX_DIFF } \\
\text { EGOV }\end{array}$ & -0.0793 & & -0.3151 & & 0.2928 & & -0.2707 & & 0.4907 & \\
\hline $\begin{array}{r}\text { INDEX_AVG } \\
\text { EGOV }\end{array}$ & & 0.0769 & & $1.2474 * *$ & & 0.0913 & & -0.255 & & 0.1441 \\
\hline INDEX_DIFF & & 0.143 & & 0.083 & & 0.0767 & & $0.4340 *$ & & 0.2677 \\
\hline BLNC_AVG & $-21.3781 * *$ & $-11.2316^{* *}$ & $-8.1999 * *$ & $-12.5804 * *$ & $-5.6874 * *$ & $-7.9844 * *$ & & & & \\
\hline BLNC_DIFF & $5.1079 * *$ & -1.4827 & $4.8266^{* *}$ & $3.4095^{*}$ & $5.3476 * *$ & 1.2488 & & & & \\
\hline CRED_AVG & $-1.4199 * *$ & $-1.8785^{* *}$ & $-2.0396 * *$ & $-2.3019 * *$ & $-2.6436^{* *}$ & -0.9356 & $-1.8552 * *$ & $-1.5333^{*}$ & $-1.8597 * *$ & $-1.8988 * *$ \\
\hline CRED_DIFF & 0.3805 & -0.2005 & 0.2822 & $-1.7271^{*}$ & 0.3085 & -0.4738 & 0.3428 & 0.727 & 0.5981 & -0.076 \\
\hline CRPT_AVG & $-2.1486^{* *}$ & $-1.4003 * *$ & & & $-1.1144 * *$ & $-1.4058 * *$ & & & & \\
\hline CRPT_DIFF & $-0.8390^{* *}$ & $-0.7500 * *$ & & & $-0.6842 * *$ & $-0.5292 *$ & & & & \\
\hline DFCT_AVG & & & $-28.6743^{* *}$ & -2.1532 & $-19.4839 * *$ & $-15.2249 * *$ & $-15.0591 * *$ & $-14.8670^{*}$ & -9.6251 & -9.2703 \\
\hline DFCT_DIFF & & & $6.4961 *$ & -6.0094 & -3.6556 & $-15.3080^{* *}$ & $-10.6288 * *$ & -5.7945 & -4.3464 & -7.3563 \\
\hline FDGDP_AVG & $-2.8024 * *$ & $-2.8794 * *$ & $2.4349 * *$ & 0.5337 & $6.0862 * *$ & $3.1809 * *$ & & & & \\
\hline FDGDP_DIFF & $7.8812^{* *}$ & 0.7017 & $5.9935^{* *}$ & $2.5778 *$ & $8.3386 * *$ & 1.1153 & & & & \\
\hline FRDM_AVG & 0.0048 & $-0.1408 * *$ & -0.0339 & $-0.3379 * *$ & $-0.0615^{*}$ & $-0.1508 * *$ & $0.1214 *$ & 0.0779 & 0.1037 & 0.0095 \\
\hline FRDM_DIFF & -0.0501 & -0.0355 & $-0.0623^{*}$ & -0.0423 & $-0.0696^{*}$ & -0.0322 & $0.1196 * *$ & 0.0737 & $0.1698 * *$ & $0.1568 *$ \\
\hline GNI_AVG & $-0.6543 * *$ & $-0.9453 * *$ & -0.0113 & $-0.7818 * *$ & -0.1113 & $-0.8723 * *$ & 0.0573 & -0.025 & 0.4333 & 0.1362 \\
\hline GNI_DIFF & $-1.3295 * *$ & -0.4661 & $-2.2102 * *$ & $-1.3997 * *$ & $-2.5637 * *$ & $-1.5213 * *$ & $-1.9254 * *$ & $-2.1586^{* *}$ & $-1.9400 * *$ & -0.4218 \\
\hline HDI_AVG & & & $-7.2897 * *$ & $-26.0877 * *$ & & & & & & \\
\hline HDI_DIFF & & & $-9.6077 * *$ & $-11.7332 * *$ & & & & & & \\
\hline INFL_AVG & $0.4271 * *$ & $0.2853 * *$ & $0.4305^{* *}$ & $0.2066^{* *}$ & $0.1984 * *$ & $0.2673 * *$ & $0.5054 * *$ & $0.6151 * *$ & 0.0063 & $0.1842^{*}$ \\
\hline INFL_DIFF & $0.0710 * *$ & 0.0338 & 0.0229 & 0.0256 & 0.019 & 0.0267 & $0.2763 * *$ & $0.3639 * *$ & $0.1592 * *$ & $0.2027 * *$ \\
\hline PDGDP_AVG & $5.7893 * *$ & $5.0940 * *$ & & & & & $-1.3152 * *$ & $-1.5386^{*}$ & $-2.0030^{*}$ & $-1.9163 *$ \\
\hline PDGDP_DIFF & $3.3664 * *$ & $3.0471 * *$ & & & & & -0.6244 & 1.9429 & -0.0595 & 1.9079 \\
\hline REV_AVG & $-27.4883^{* *}$ & $-23.8383 * *$ & $-18.2798 * *$ & $-14.3671 * *$ & $-18.2013^{* *}$ & $-16.3598 * *$ & 6.4451 & 3.0877 & 5.9016 & -3.4063 \\
\hline REV_DIFF & $-6.6482 *$ & -1.4823 & 2.5782 & -1.6382 & 3.0967 & 0.7942 & 11.2746 & -5.355 & 14.9208 & -2.6734 \\
\hline TAX_AVG & $13.1445^{* *}$ & $12.6820 * *$ & 3.9869 & $11.9538 * *$ & $9.8890 * *$ & $15.3338 * *$ & 4.758 & 4.9987 & 5.7957 & 3.8368 \\
\hline TAX_DIFF & -3.7567 & -2.599 & $-13.6511^{*}$ & 1.595 & -6.8992 & 2.4957 & -6.2944 & -7.0685 & -14.7519 & 12.4545 \\
\hline UNPL_AVG & $15.0102 * *$ & $13.6229 * *$ & 1.5712 & $-22.3987 * *$ & $22.9896^{* * *}$ & -2.9153 & $14.4326^{*}$ & 14.0502 & 1.8062 & 1.6713 \\
\hline UNPL_DIFF & 6.9450 & $23.9304 * *$ & 3.1431 & $15.5387 * *$ & 7.0609 & $17.4340^{* *}$ & 1.234 & -7.9154 & -1.5318 & -10.3711 \\
\hline DFLT75 & & & $1.7705^{* *}$ & $2.2268 * *$ & & & & & & \\
\hline DFLT95 & & & $-0.8798 * *$ & $-1.2830 * *$ & & & & & & \\
\hline EURO & $-1.2289 * *$ & $-1.5018 * *$ & $-2.9056^{* *}$ & -0.4082 & $-4.6373 * *$ & $-4.4391 * *$ & $-2.0334 * *$ & $-1.9049 * *$ & -1.1368 & -0.2408 \\
\hline OECD & $-1.3772 * *$ & -0.4447 & $-3.4959 * *$ & $-1.4065^{* *}$ & $-1.5374 * *$ & -0.0184 & -0.1322 & -0.1766 & -0.5455 & -0.4593 \\
\hline LGLGRM & -0.0421 & -0.1645 & $-1.3138^{*}$ & 0.0082 & 0.521 & 0.0254 & & & & \\
\hline LGLSKN & $5.7561^{* *} *$ & $3.0595 * *$ & -1.3755 & $-2.5701 * *$ & & & -1.1393 & -0.779 & -0.8109 & 0.1221 \\
\hline LGLSOC & & & & & & & $-3.9525 * *$ & $-3.0599 * *$ & $-1.9804 *$ & -0.6457 \\
\hline LGLUK & $-2.6457 * *$ & $-1.6721 * *$ & $-2.9786^{* *}$ & $-1.6311 * *$ & $-1.0852 * *$ & $-1.0471 * *$ & $-1.2400 * *$ & $-1.3055^{*}$ & -0.9219 & -0.3666 \\
\hline CONS & & & & & & & -1.2054 & 1.2552 & -5.1552 & 3.069 \\
\hline Loglik & -416.13 & -332.18 & -416.58 & -543.70 & -414.09 & -348.23 & & & & \\
\hline R-squared & & & & & & & 0.7425 & 0.7427 & 0.5283 & 0.5158 \\
\hline $\mathrm{Rho}^{\mathrm{a}}$ & 0.8683 & 0.7806 & 0.7987 & 0.8478 & 0.8597 & 0.757 & 0.2635 & 0.4222 & 0.3224 & 0.3515 \\
\hline N. Obs & 502 & 320 & 472 & 320 & 492 & 320 & 357 & 175 & 438 & 462 \\
\hline
\end{tabular}


Table 12. Introducing number of patents or internet users in baseline regressions as a robustness check.

\begin{tabular}{|c|c|c|c|c|c|c|c|c|c|}
\hline \multirow[b]{2}{*}{ NRI_AVG } & \multicolumn{2}{|c|}{$\begin{array}{c}\text { RTGSP } \\
\text { (Random Effects) } \\
\end{array}$} & \multicolumn{2}{|c|}{$\begin{array}{c}\text { RTGM } \\
\text { (Random Effects) } \\
\end{array}$} & \multirow{2}{*}{$\begin{array}{c}\begin{array}{c}\text { RTGF }^{16} \\
\text { (Random }^{\text {Effects) }}\end{array} \\
-0.8398^{* *}\end{array}$} & \multicolumn{2}{|c|}{$\begin{array}{c}\text { YTM } \\
\text { (Random Effects) } \\
\end{array}$} & \multicolumn{2}{|c|}{$\begin{array}{c}\text { exCoD } \\
\text { (Random Effects) } \\
\end{array}$} \\
\hline & $-0.7152 *$ & $-0.7829 * *$ & $-2.0419 * *$ & $-1.9878 * *$ & & -0.9989 & -1.0379 & $-1.7962 *$ & -1.2660 \\
\hline NRI_DIFF & 0.1109 & 0.0261 & $0.6664 *$ & 0.2276 & -0.0157 & 0.2583 & 0.2346 & 0.4725 & 0.5097 \\
\hline PTNTS_AVG & -3.1767 & & -4.4085 & & & -0.6349 & & 0.5568 & \\
\hline PTNTS_DIFF & $-9.1030 *$ & & 1.812 & & & -1.3747 & & -2.855 & \\
\hline INTUSRS_AVG & & $-1.6639 *$ & & 1.2788 & -1.2752 & & -0.1069 & & -1.5293 \\
\hline INTUSRS_DIFF & & 0.6995 & & $1.8388 *$ & $2.5633 * *$ & & $-2.6015^{* *}$ & & $-7.0400 * *$ \\
\hline BLNC_AVG & $-8.5969 * *$ & $-13.1163^{* *}$ & $-14.3804 * *$ & $-3.1830 * *$ & $-10.6329 * *$ & & & & \\
\hline BLNC_DIFF & 0.7785 & -0.4070 & 0.9323 & 0.6215 & 0.9641 & & & & \\
\hline CRED_AVG & $-0.7947 * *$ & $-1.2406 * *$ & $-2.4674 * *$ & $-1.8487 * *$ & $-1.5046 * *$ & $-1.8671 * *$ & $-1.8360 * *$ & $-1.9462 * *$ & $-1.8800 * *$ \\
\hline CRED_DIFF & 0.3648 & -0.3759 & $-1.3210 * *$ & $-1.9599 * *$ & -0.5028 & 0.2118 & 0.6979 & 0.3516 & $1.3313^{*}$ \\
\hline CRPT_AVG & $-1.5190 * *$ & $-1.2838 * *$ & & & $-1.1717 * *$ & & & & \\
\hline CRPT_DIFF & $-0.5630 * *$ & $-0.5027 * *$ & & & $-0.3728 *$ & & & & \\
\hline DFCT_AVG & & & $-7.5424 *$ & $-19.9207 * *$ & $-15.5727 * *$ & $17.2228 * *$ & $-16.0318 * *$ & -9.4692 & -8.1883 \\
\hline DFCT_DIFF & & & -0.2904 & -1.4402 & $-4.9662 *$ & $-9.8400 * *$ & $-8.9087 * *$ & -4.474 & -3.2247 \\
\hline FDGDP_AVG & 1.4521 & -0.4892 & $2.0346^{* *}$ & $1.7106^{* *}$ & $4.0869^{* *}$ & & & & \\
\hline FDGDP_DIFF & $5.5114 * *$ & 1.7677 & $5.4005^{* *}$ & $2.0087 * *$ & $2.8446^{* *}$ & & & & \\
\hline FRDM_AVG & -0.0071 & -0.0098 & -0.0236 & $-0.0721 * *$ & 0.0083 & $0.0980^{*}$ & $0.0923 * *$ & 0.0704 & 0.0693 \\
\hline FRDM_DIFF & $-0.0643^{*}$ & $-0.0856^{* *}$ & $-0.0947 * *$ & $-0.0950 * *$ & $-0.1004 * *$ & $0.1118 * *$ & $0.1312 * *$ & $0.1871 * *$ & $0.1951 * *$ \\
\hline GNI_AVG & $-0.4129 * *$ & $-0.2878 * *$ & 0.0613 & 0.1138 & $-0.1932 * *$ & 0.0297 & -0.0103 & 0.4472 & 0.3782 \\
\hline GNI_DIFF & $-1.0783 * *$ & $-0.7392 *$ & $-2.0444 * *$ & $-1.7438 * *$ & $-2.0014 * *$ & $-2.0308 * *$ & $-1.3183 * *$ & $-1.6621 * *$ & 0.3679 \\
\hline HDI_AVG & & & $-16.8709 * *$ & $-3.8655 * *$ & & & & & \\
\hline HDI_DIFF & & & $-10.6222 * *$ & $-7.1571^{* *}$ & & & & & \\
\hline INFL_AVG & $0.4546^{* *}$ & $0.3123 * *$ & $0.2449 * *$ & $0.2858 * *$ & $0.3427 * *$ & $0.5155^{* *}$ & $0.5272 * *$ & 0.0632 & 0.0795 \\
\hline INFL_DIFF & $0.0850 * *$ & $0.0457 * *$ & 0.0269 & 0.0185 & $0.0251 *$ & $0.2568 * *$ & $0.2512 * *$ & $0.1497 * *$ & $0.1484 * *$ \\
\hline PDGDP_AVG & $2.4803 * *$ & $3.0067 * *$ & & & & $-1.3381^{*}$ & $-1.3143 * *$ & $-1.9725^{*}$ & $-2.0240^{*}$ \\
\hline PDGDP_DIFF & $5.4276 * *$ & $4.2142 * *$ & & & & -0.4069 & 0.6084 & 0.3337 & $3.1429 * *$ \\
\hline REV_AVG & $-20.6497 * *$ & $-15.4432 * *$ & $-8.2587 * *$ & $-11.2448 * *$ & $-9.2871 * *$ & 6.1604 & $5.9102 *$ & 5.2743 & 4.4948 \\
\hline REV_DIFF & $-10.6892 *$ & -3.8457 & -1.6055 & 4.9805 & 2.2381 & 9.0643 & 7.3674 & $15.7345^{*}$ & 6.1358 \\
\hline TAX_AVG & $6.9118 * *$ & $7.6845^{* *}$ & 1.1169 & $8.5064 * *$ & $9.9127 * *$ & 2.116 & 2.1666 & 2.5143 & 1.8649 \\
\hline TAX_DIFF & 2.8854 & -3.6267 & -1.5574 & -3.2721 & -2.8883 & -6.9574 & -8.9627 & -13.1004 & -10.3927 \\
\hline UNPL_AVG & 3.2864 & $-4.4886^{*}$ & $-21.1388 * *$ & $-4.3963 *$ & $-5.4851 * *$ & 10.2275 & 10.8215 & -2.7914 & -0.9388 \\
\hline UNPL_DIFF & $11.0483^{* *}$ & $20.4904^{* *} *$ & $7.6330 *$ & $13.0458 * *$ & $17.4193 * *$ & 2.6761 & 0.7777 & 0.298 & -2.7079 \\
\hline DFLT75 & & & $1.9075^{* *}$ & $0.5785^{* *}$ & & & & & \\
\hline DFLT95 & & & $-2.0464 * *$ & $-0.9841 * *$ & & & & & \\
\hline EURO & $-3.0787 * *$ & $-2.1396 * *$ & $-1.9597 * *$ & $-2.5813^{* *}$ & $-4.3686^{* *}$ & $-2.1276^{* *}$ & $-2.1032 * *$ & -0.9256 & -1.0653 \\
\hline OECD & $-1.2276^{* *}$ & $-2.2256^{* *}$ & $-1.3512 * *$ & $-2.9103 * *$ & $-1.5390 * *$ & -0.5489 & -0.2965 & -0.8745 & -0.4374 \\
\hline LGLGRM & -0.1057 & $-1.2571 *$ & $1.2587^{*}$ & 0.4668 & $-1.6663^{* *}$ & & & & \\
\hline LGLSKN & $2.0796 * *$ & $2.5492 * *$ & 0.5425 & -0.0575 & & -0.6707 & -0.7067 & 0.1116 & 0.0456 \\
\hline LGLSOC & & & & & & $-3.8028 * *$ & $-3.7994 * *$ & -1.3695 & -1.5004 \\
\hline LGLUK & $-2.4889 * *$ & $-1.6598 * *$ & $-1.0965^{* *}$ & $-1.1393 * *$ & $-1.2017 * *$ & $-1.1378^{*}$ & $-0.9674 *$ & 0.0117 & -0.2586 \\
\hline _CONS & & & & & & 1.9785 & 3.3335 & -1.7712 & -1.4567 \\
\hline Loglik & -485.10 & -623.10 & -527.80 & -673.42 & -643.52 & & & & \\
\hline R-squared & & & & & & 0.7417 & 0.7437 & 0.5158 & 0.5375 \\
\hline Rho $^{\mathrm{a}}$ & 0.8656 & 0.8181 & 0.8724 & 0.8229 & 0.7916 & 0.3823 & 0.1759 & 0.3515 & 0.3559 \\
\hline N. Obs & 557 & 646 & 557 & 646 & 646 & 354 & 360 & 462 & 496 \\
\hline
\end{tabular}

${ }^{16}$ We do not provide estimates for Fitch concerning PTNTS because our maximum-likelihood estimation did not converge. 
Table 13. Controlling for labour productiveness and growth. Total sample.

\begin{tabular}{|c|c|c|c|c|c|}
\hline & $\begin{array}{c}\text { RTGSP } \\
\text { (Random Effects) }\end{array}$ & $\begin{array}{c}\text { RTGM } \\
\text { (Random Effects) }\end{array}$ & $\begin{array}{c}\text { RTGF } \\
\text { (Random Effects) }\end{array}$ & $\begin{array}{c}\text { YTM } \\
\text { (Random Effects) }\end{array}$ & $\begin{array}{c}\operatorname{exCoD}^{\mathbf{b}} \\
\text { (Random Effects) }\end{array}$ \\
\hline NRI_AVG & -0.0876 & $-1.6920^{* *}$ & 0.2459 & 0.0244 & -1.0325 \\
\hline NRI_DIFF & 0.0213 & 0.2012 & 0.0001 & 0.1864 & 0.3739 \\
\hline BLNC_AVG & $-9.0355 * *$ & -0.743 & $-4.2766 * *$ & & \\
\hline BLNC_DIFF & 0.678 & 1.3116 & 1.087 & & \\
\hline CRED_AVG & $-1.2338 * *$ & $-1.6742 * *$ & -0.3074 & $-2.3418 * *$ & -1.4018 \\
\hline CRED_DIFF & -0.1593 & $-1.3364 * *$ & -0.0311 & 0.2904 & -1.0616 \\
\hline CRPT_AVG & $-1.3031 * *$ & & $-1.3877 * *$ & & \\
\hline CRPT_DIFF & $-0.4424 * *$ & & $-0.3717^{*}$ & & \\
\hline DFCT_AVG & & $-22.9847 * *$ & $-24.5198 * *$ & $-11.1986^{* *}$ & -6.2814 \\
\hline DFCT_DIFF & & -2.7691 & $-5.9231 * *$ & $-7.9223^{*}$ & -0.5594 \\
\hline FDGDP_AVG & $-4.8389 * *$ & $0.8721 *$ & $3.7634 * *$ & & \\
\hline FDGDP_DIFF & 0.2306 & 0.8535 & 1.1677 & & \\
\hline FRDM_AVG & $0.0450 * *$ & $-0.0548 * *$ & -0.0264 & $0.0822 * *$ & 0.0657 \\
\hline FRDM_DIFF & $-0.0779 * *$ & $-0.0776^{* *}$ & $-0.0947 * *$ & $0.1050^{* *}$ & $0.1355^{* *}$ \\
\hline GDPG_AVG & 3.0755 & -4.7191 & -4.9139 & $-55.6289 * *$ & -0.4582 \\
\hline GDPG_DIFF & $-4.3926 * *$ & -0.775 & $-4.4976 * *$ & -4.1456 & $-7.0129 *$ \\
\hline GNI_AVG & $-0.3112 * *$ & $0.1542 *$ & $-0.4366 * *$ & -0.1173 & \\
\hline GNI_DIFF & -0.4682 & $-1.3932 * *$ & $-1.5288 * *$ & $-2.3802 * *$ & \\
\hline HDI_AVG & & 2.3165 & & & \\
\hline HDI_DIFF & & $-7.7415^{* *}$ & & & \\
\hline INFL_AVG & $0.3974 * *$ & $0.2920 * *$ & $0.3983^{* *}$ & $0.5800^{* *}$ & 0.1358 \\
\hline INFL_DIFF & $0.0519 * *$ & 0.0188 & $0.0274 *$ & $0.2519^{* *}$ & $0.1488 * *$ \\
\hline LPROD_AVG & $-1.0922 * *$ & $-0.8597 * *$ & -0.0804 & $-0.7548 * *$ & -0.5326 \\
\hline LPROD_DIFF & $-2.1500^{*}$ & -0.6373 & -0.3307 & 1.4126 & $-2.7421^{*}$ \\
\hline PDGDP_AVG & $4.4134 * *$ & & & $-1.2004 * *$ & -1.6567 \\
\hline PDGDP_DIFF & $2.4736^{* *}$ & & & -0.3895 & 1.5976 \\
\hline REV_AVG & $-12.1798^{* *}$ & $-10.5006^{* *}$ & $-11.0002 * *$ & 2.6087 & 9.0046 \\
\hline REV_DIFF & -1.0561 & $5.7291 *$ & 2.6431 & 6.5397 & 5.158 \\
\hline TAX_AVG & $15.8569^{* *}$ & $10.6704^{* *}$ & $8.4098^{* *}$ & 2.3078 & -2.0125 \\
\hline TAX_DIFF & 0.9084 & 0.681 & 0.9132 & -6.2384 & -1.981 \\
\hline UNPL_AVG & -1.4327 & 2.0566 & $-3.5243 *$ & $17.2574 * *$ & 0.8622 \\
\hline UNPL_DIFF & $20.0805^{* *}$ & $12.3087^{* *}$ & $15.5823^{* *}$ & 1.0247 & 4.1917 \\
\hline DFLT75 & & $0.7987 * *$ & & & \\
\hline DFLT95 & & $-0.7359 * *$ & & & \\
\hline EURO & -0.4846 & $-2.0955^{* *}$ & $-3.6932 * *$ & $-1.8591 * *$ & -1.1133 \\
\hline OECD & $-2.0211 * *$ & $-2.8058 * *$ & $-1.7975 * *$ & -0.3546 & -0.3051 \\
\hline LGLGRM & $-2.4228 * *$ & $0.8053^{*}$ & -0.4061 & & \\
\hline LGLSKN & $0.9796^{*}$ & 0.9675 & & -0.9417 & -0.8909 \\
\hline LGLSOC & & & & $-3.3001 * *$ & $-1.8886^{*}$ \\
\hline LGLUK & $-2.8726^{* *}$ & $-0.9841 * *$ & $-1.4033 * *$ & -0.5633 & -0.1938 \\
\hline _CONS & & & & $12.4686^{* *}$ & $10.8841^{* *}$ \\
\hline Loglik & -653.44 & -689.61 & -674.41 & & \\
\hline R-squared & & & & 0.7587 & 0.4932 \\
\hline $\mathrm{Rho}^{\mathrm{a}}$ & 0.8305 & 0.8020 & 0.7556 & 0.0734 & 0.3266 \\
\hline N. Obs & 650 & 650 & 650 & 360 & 496 \\
\hline
\end{tabular}

Notes: The coefficient with the variable followed by_AVG denotes the long-run coefficient while the coefficient with the variable followed by DIFF denotes the short-run coefficient. Errors are standard. $(*),(* *)$ denotes statistical significance at 5 percent, 1 percent.

${ }^{-}$Fraction of variance that occurs at country level or the intraclass correlation.

${ }^{b}$ GNI is dropped due to multicollinearity. 
Figure 1. Scatterplot between YTM and NRI (Year 2010) and bivariate regression line by OECD membership

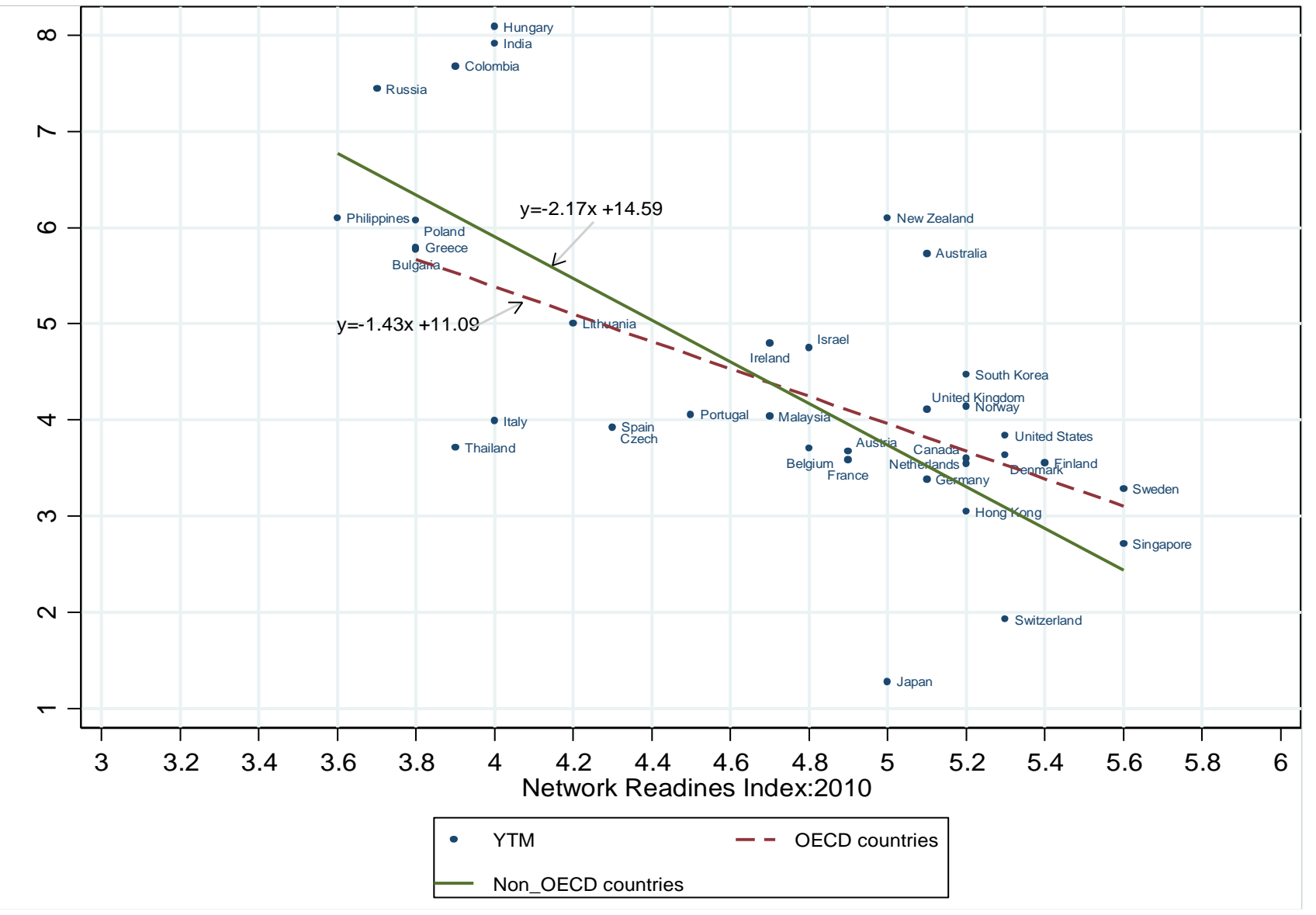

